\title{
1 CURRENT KNOWLEDGE ON THE MELATONIN SYSTEM IN TELEOST FISH
}

2

3 Falcón J. ${ }^{1,2}$, Migaud H. ${ }^{3}$, Muñoz-Cueto J.A. ${ }^{4}$, Carrillo M. ${ }^{5}$

4

$7{ }^{1}$ CNRS, UMR 7628 et GDR 2821, Modèles en Biologie cellulaire et évolutive, Avenue 8 Fontaulé, BP 44, F-66651 Banyuls-sur-Mer, Cedex, France

$9{ }^{2}$ Université Pierre et Marie Curie (UPMC), UMR 7628 et GDR 2821, Laboratoire Arago, 10 Avenue Fontaulé, BP 44, F-66651 Banyuls-sur-Mer, Cedex, France

$11{ }^{3}$ University of Stirling, Institute of Aquaculture, Genetics and Reproduction Group, Stirling, 12 FK9 4LA. UK.

$13{ }^{4}$ Departamento de Biología, Facultad de Ciencias del Mar y Ambientales, Universidad de 14 Cádiz, E-11510 Puerto Real, Spain

$15{ }^{5}$ Department of Fish Physiology and Biotechnology, Instituto de Acuicultura de Torre la Sal, 16 Consejo Superior de Investigaciones Científicas (CSIC), 12595 Torre la Sal, Ribera de 17 Cabanes s/n, Castellón, Spain

Corresponding author: Jack Falcón, Laboratoire Aragó, UMR 7628/GDR2821, Université 20 Pierre et Marie Curie (UPMC) and CNRS, B.P. 44, Avenue du Fontaulé, F-66651, France 21 Banyuls-Sur-Mer Cedex, France.

22 Phone: +33/0 4688873 92; FAX: +33/0 4688873 98; e-mail: falcon@,obs-banyuls.fr 
Key words: Fish, reproduction, photoperiod, melatonin, circadian, circannual

Melatonin is a much conserved feature in vertebrates that plays a central role in the entrainment of daily and annual physiological rhythms. Investigations aiming at understanding how melatonin mediates the effects of photoperiod on crucial functions and behaviors have been very active in the last decades, particularly in mammals. In fish a clearcut picture is still missing. Here we review the available data on (i) the sites of melatonin production in fish, (ii) the mechanisms that control its daily and annual rhythms of production and (iii) the characterization of its different receptor subtypes, their location and regulation. The in vivo and in vitro data on melatonin effects on crucial neuroendocrine regulations, including reproduction, growth, feeding and immune response, are also reviewed. Finally we discuss how manipulation of the photic cues impact on fish circannual clock and annual cycle of reproduction, and how this can be used for aquaculture purposes. 
1. INTRODUCTION

2. THE SOURCES OF MELATONIN PRODUCTION

2.1. The pineal gland

2.1.1 Functional anatomy of the pineal organ

\subsubsection{Nocturnal melatonin biosynthesis in the pineal photoreceptor cells}

2.2. The retina and melatonin production

4. MELATONIN EFFECTS

4.1. Reproduction

4.2. Growth and feeding

4.3. Immune system

4.4. Conclusions

\section{IMPLICATIONS FOR AQUACULTURE}

5.1. Photic manipulation of fish physiology

5.2. Light sensitivity

5.3. Circannual Rhythms and the Endogenous Control of Reproduction 


\section{INTRODUCTION}

67

Virtually all organisms have adapted their behaviors and functions to the daily and annual variations of the external cues. The alternation of light (L) and darkness (D), the $24 \mathrm{~h}$ LD cycle, is the most prominent and reliable of these cues (noise free signal) but others, such as temperature, food availability, rainfall or water salinity, may also shape the rhythms. In fish, larval development, locomotor activity, sedation, skin pigmentation, oxygen consumption, thermoregulation, food intake and shoaling behaviour are among a number of functions that display daily rhythms (Ekström and Meissl, 1997; Falcón et al., 2007a). Horizontal migration (salmonids), growth, immune system and reproduction are the main functions known to exhibit annual rhythms, particularly in fish living in temperate and arctic areas. In some cases, these daily and annual rhythms are just a passive, on/off, type of response to the variations in photoperiod and temperature. In other (most?) cases, however, they are driven by internal clocks that free-run with a period close to $24 \mathrm{~h}$ (circadian rhythms) or one year (circannual rhythms) under constant conditions. Organisms equipped with such time measurement systems are able to predict and anticipate environmental changes, so that the right event will occur at the right time. This is a major improvement if one considers the number of more or less inter-dependent events that cycle on a $24 \mathrm{~h}$ and on an annual basis, from molecules to organisms, and from populations to ecosystems. If there is quite a huge amount of information on the mechanisms underlying circadian rhythms very little is known on those mechanisms driving the circannual rhythms (Bradshaw and Holzapfel, 2007; Paul et al., 2008).

A circadian system comprises all the different components by which light enters the organism and is transformed into a timed nervous or hormonal signal. The core of the system is made of a clock machinery, whose autonomous activity is synchronized to the prevailing 24 
91 h LD cycle by light perceived through specific light sensors; in turn, the clocks drive the 92 production of rhythmic output signals. Melatonin is one major output of the vertebrates' circadian clocks, which conveys rhythmic information to the organism. The daily pattern of melatonin secretion is much conserved among vertebrates, in which the pineal organ produces melatonin at night; this results in blood and cerebrospinal fluid melatonin levels that are high at night and low during day. This constancy emphasizes the key role the hormone plays in vertebrates. However, the organization of the circadian system that controls this melatonin rhythm has changed dramatically in vertebrates. In mammals, the photic information is perceived through the eyes and conveyed, through a retino-hypothalalamic tract (RHT), to the suprachiasmatic nuclei of the hypothalamus $(\mathrm{SCN})$, where the master clocks reside; from there, a multisynaptic pathway (hypothalamic paraventricular nuclei $[\mathrm{PVN}] \rightarrow$ preganglionic neurons of the sympathetic nervous system $\rightarrow$ superior cervical ganglion [SCG]) connects the $\mathrm{SCN}$ to the pineal gland, the melatonin producing unit (Fig. 1) (Simonneaux and Ribelayga, 2003). In fish and other non mammalian vertebrates, the circadian system is organized as a network of more or less tightly interconnected circadian systems (Fig. 1) (Falcón et al., 2007). In all cases, the pineal organ and retina occupy a central position in this circadian organization.

What are the neuro-anatomical and functional basis of the rhythms? How are they synchronized and entrained? How do they impact on overt rhythms? These are some of the questions of crucial interest for our understanding of both the regulation of basic fish physiological functions and the control of fish maintenance, growth and reproduction for aquaculture purposes. The present review summarizes our current knowledge on the organization of time measurement systems in fish (circadian axis), with special emphasis on melatonin as the time-keeping hormone that impacts on crucial physiological functions, including growth and reproduction. 


\section{THE SOURCES OF MELATONIN PRODUCTION}

\subsection{The pineal gland}

\section{$\underline{\text { 2.1.1 Functional anatomy of the pineal organ }}$}

In most species investigated, the pineal organ appears as a vesicle attached to the roof

123 of the diencephalon by a slender stalk; it is usually located below a window in the skull through which light enters. The vesicle is made of a pseudo-stratified epithelium that is opened to the cerebrospinal fluid (CSF); folliculated (as in birds) as well as compact (as in mammals) glands have also been described (Omura and Oguri, 1969; Ekström and Meissl, 2003). The pineal epithelium is made of true cone-like photoreceptor cells and of ependymal interstitial cells that contact the CSF in their most apical part (Falcón, 1999). The photoreceptor cells establish synaptic contacts with second order neurons that send their axons to the brain. The pineal organ thus resembles very much to a simplified retina, and the structural and functional analogies between the two organs have been extensively reviewed in

132 the past (O'Brien and Klein, 1986; Ekström and Meiss1, 1997; Falcón, 1999; Falcón et al., 133 2007b).

The pineal photoreceptors share more than structural analogies with the retinal cones

135 (Ekström and Meiss1, 1997; Falcón, 1999; Falcón et al., 2007b). As true light sensitive 136 photoreceptors, they have a similar composition in lipids and proteins of the

137 phototransduction cascade (opsins, transducin, arrestin, cyclic nucleotide gated channel). And,

138 their electrical response to light stimuli is similar: light induces a dose-dependent cell 139 hyperpolarization that results in the inhibition of an excitatory neurotransmitter (aspartate or 140 glutamate). In the pineal organ, the excitatory neurotransmitter reaches directly the ganglion 141 cells, which send their axons to the brain. Thus, the signals that are conveyed to the brain 
142 reflect mainly the response of the photoreceptor cells, i.e., the pineal organ is a luminance

143 detector that provides information on light intensity, spectral content and duration of day-

144 length. It is interesting that the pineal and retinal ganglion cells may target similar brain areas,

145 particularly in the thalamus and pretectum (Ekström and Meissl, 1997).

146 In addition to the excitatory neurotransmitter, the pineal and retinal photoreceptors

147 both produce melatonin at night, following cell depolarization (Falcón, 1999; Falcón et al., 148 2007b)

\subsubsection{Nocturnal melatonin biosynthesis in the pineal photoreceptor cells}

Melatonin is synthesized from tryptophan taken up by the pineal cells (Fig. 2). Two

152 enzymatic steps allow the formation of serotonin from tryptophan: Tryptophan hydroxylation, catalyzed by tryptophan hydroxylase $(\mathrm{TpOH})$, allows the synthesis of hydroxytryptophan, which is then decarboxylated by the aromatic aminoacid decarboxylase, leading to the formation of serotonin. Another two enzymatic steps transform serotonin into melatonin: the arylalkylamine $N$-acetyltransferase (AANAT) catalyses the formation of $N$-acetylserotonin, and the hydroxyindole- $O$-methyltransferase (HIOMT) converts the $\mathrm{N}$-acetylserotonin formed into melatonin (Falcón, 1999; Falcón et al., 2007a,b). While serotonin levels are high during the day and decrease at night, melatonin levels present a shifted pattern with elevated levels at night and basal levels during the day (Falcón 1999; Bromage et al., 2001). The nocturnal rise in melatonin production by the pineal reflects an increase in AANAT activity, whereas HIOMT activity remains steady throughout the LD cycle.

Teleost fish are special because unlike all other vertebrates, they possess two AANAT genes, probably as a result of genome duplications (Falcón et al., 2007). And, the so-called AANAT1 and AANAT2 display tissue specific distribution: AANAT1 is more specifically expressed in the retina and brain, whereas AANAT2 is more specifically expressed in the 
167 pineal organ. Recently it was found that more distant teleost even possess two AANAT1 (1a

168 and 1b; Coon et al., 2006). This has implications in terms of photic regulation of melatonin 169 production.

\section{$\underline{\text { Light and circadian control of pineal AANAT2 activity and melatonin production }}$}

Light inhibits AANAT2 activity and melatonin release in vivo or in vitro. At night,

172 photoreceptor depolarization allows calcium $\left(\mathrm{Ca}^{2+}\right)$ entry (through voltage-gated $\mathrm{Ca}^{2+}$

173 channels) and cyclic AMP (cAMP) accumulation (Falcón, 1999). Both contribute to increase

174 AANAT2 amount and activity through phosphorylation of the AANAT2 protein. This process

175 is reversed by illumination, which sequentially induces photoreceptor hyperpolarization,

176 dephosphorylation and degradation of AANAT2 through proteasomal proteolysis, resulting in

177 the decrease of melatonin production (Falcón et al., 2001). The light-induced decrease in

178 AANAT2 activity and melatonin secretion is a dose-dependent process (Fig. 3; Migaud et al.,

179 2006), as it is the case for the inhibition of the neurotransmitter release, and depends on the

180 spectral composition of the light. In trout, inhibition is seen with the short wavelengths of the

181 visible spectrum (Max and Menaker, 1992). This situation applies in salmonid fish in which

182 the pineal photoreceptor cell integrates the light signal; this allows controlling the amount of

183 melatonin produced in an on/off manner (Fig. 4; Falcón 1999; Falcón et al., 2007; ligo et al.,

184 2007). In this scheme, AANAT2 messenger RNA (mRNA) is made available at night, when

185 AANAT2 is allowed to increase, or is constitutively expressed. As a consequence, continuous

186 light (LL) suppresses melatonin secretion, whereas constant darkness (DD) results in

187 constantly high levels of melatonin secretion. But in a majority of teleost species the response

188 to light is not as passive as in the case of salmonids. This is because the control in melatonin

189 secretion involves a circadian clock system located within the photoreceptor cells themselves

190 (Bolliet et al., 1996). Extensive discussion on how such a time-keeping mechanism operates

191 and is entrained by light is available elsewhere (Cahill, 2002; Reppert and Weaver, 2002). 
Briefly, the circadian clock machinery is based on a molecular feed-back loop consisting of

193 two heterodimers, PER/CRY acting as repressors and BMAL/CLOCK acting as activators, 194 and additional interlocking loops. BMAL/CLOCK heterodimers also drive the rhythmic 195 expression of a number of genes including the Aanat2, which thus appears as a direct output 196 gene of the circadian clock (Appelbaum et al., 2004, 2006; Zilberman-Peled et al., 2007). 197 Transcription of Aanat2 allows accumulation of AANAT mRNA later during the day and 198 early at night making AANAT production possible as soon as night starts. Morning light resets the clock (Ziv et al., 2005) and inhibits AANAT activity and melatonin secretion (Fig. 3). The presence of such a circadian clock allows the system anticipating changes in the LD conditions. This explains that under LL only the AANAT2 mRNA rhythm is maintained, 202 whereas under DD, the rhythms in AANAT2 mRNA abundance, AANAT2 activity and 203 melatonin secretion are maintained for days (Falcón 1999; Falcón et al., 2007; Martinez204 Chavez et al., 2008).

The diversity of the responses to light among fish may reflect specific adaptations to 206 their environment, where light may vary in terms of quantity (intensity), quality (spectral 207 content) and duration (photoperiod) (Sumpter, 1992; Boeuf and Le Bail, 1999). Intensity and 208 spectral composition are prone to daily variations, particularly underwater, depending on the time of day (dawn and dusk), weather conditions or moon phase. These parameters are likely to affect the amplitude of the melatonin signal through a direct control on AANAT2 protein 211 amount and enzymatic activity. In contrast, photoperiod (duration) is considered as a "noise 212 free" signal as it remains constant over the years and reflects seasonality depending on the 213 latitude. This signal is integrated by the clock machinery. In tropical areas, the phase of the 214 rhythm is locked to the 12L/12D cycle and displays remarkable stability (Martinez-Chavez et 215 al., 2008), whereas in temperate regions, the phase is adjusted day after day (Ziv et al., 2005).

\section{$216 \quad$ Temperature and melatonin biosynthesis}


Fish are ectotherms and as such they are directly influenced by the external 218 temperature, which fluctuates on a daily and seasonal basis. Studies have shown that 219 temperature acts directly on the pineal organ to modulate melatonin secretion, through the regulation of AANAT2 activity (Benyassi et al., 2000; Coon et al., 1999; Falcón, 1999; Falcón et al., 1994, 1996; Zachmann et al., 1992). Interestingly, (i) there is a good correlation between the peak of AANAT2 response and the fish optimal physiological temperature (trout: $12^{\circ} \mathrm{C}$, pike: $20^{\circ} \mathrm{C}$, seabream: $27^{\circ} \mathrm{C}$; zebrafish: $30^{\circ} \mathrm{C}$ ); (ii) the response to temperature is an intrinsic property of the enzyme itself, because the same response curves were obtained when activities were measured from cultured pineal organ homogenates or recombinant AANAT2 enzymes. In the pike, temperature had no effect on the phase and period of the circadian rhythm) (Falcón et al., 1994). Thus, the concurrent action of photoperiod, that determines the 228 duration of the melatonin signal, and of temperature, that determines its amplitude, provide accurate definitions of both the daily and annual cycles. Any change in temperature, related to husbandry conditions or global warming, may thus have dramatic consequences on the time-

\section{1 keeping system of fish.}

\section{Internal factors and melatonin biosynthesis}

The role played by internal factors in the control of melatonin production has received

234 little attention. The data available is limited to few fish species, so that no general rule can be extrapolated (review in Falcón et al., 2007). Among these factors is melatonin itself (high concentrations inhibit its own production), neurotransmitters/neuromodulators produced 237 locally (adenosine, GABA) or out of the pineal (norepinephrine), and hormones 238 (glucocorticoïds, sexual steroids). For some of these factors (melatonin, adenosine), this 239 represents a fine-tuning internal mechanism; for others (steroids) they might reflect a feed240 back loop within melatonin regulated processes. The case of norepinephrine deserves special 241 attention. Indeed, in mammals, norepinephrine is the final link in the pathway that brings light 
242 information from the eyes to the pineal gland, through the circadian clocks of the SCN (Klein 243 et al., 1997): the nocturnal release of the neurotransmitter synergistically activates $\alpha 1-$ and $244 \alpha 2$-adrenergic receptors to stimulate nocturnal melatonin secretion. This is because the 245 mammalian pinealocyte has lost any direct photosensitivity and circadian clock properties; the 246 photoperiodic and circadian control of melatonin secretion relies exclusively on the 247 RHT/SCN/SCG pathway (Fig. 1). An intermediate situation is seen in birds, which possess 248 both a direct and an indirect photosensitivity, and where light and norepinephrine acting 249 through $\alpha 2$-adrenergic receptors, concomitantly inhibit daytime melatonin secretion. The 250 existence of a norepinephrine control of melatonin secretion in some, but not all, fish species 251 might reflect the existence of a convergent evolution of the pathways involved in the control 252 of melatonin production. Three arguments favor this view. First, a norepinephrine control has 253 been demonstrated in the pike pineal gland, which possesses both 'typical' as well as 254 'rudimentary' photoreceptor cells, but not in trout pineal gland, which has only 'typical' cone 255 like photoreceptors (Falcón, 1999). Second, Migaud et al. (2007) has recently shown that at 256 least three categories of fish may be distinguished depending on whether the photoperiodic 257 control of melatonin production by the pineal gland relies on the pineal itself, or the eyes, or 258 both. Third, in contrast to the situation observed in vitro (see above), trout pineal AANAT 259 activity as well as serotonin and melatonin contents do oscillate on a circadian basis in vivo, 260 i.e., in animals maintained under constant darkness (Ceinos et al., 2008). This would suggest 261 that the circadian organization that controls pineal melatonin secretion is likely to depend on a 262 retinal/brain pathway in trout as is the case in mammals. Future studies should aim at 263 exploring this point.

\subsection{The retina and melatonin production}


268 might be, as mentioned above, through controlling pineal melatonin secretion, although this 269 remains to be fully demonstrated. The second is through its own production. In most 270 vertebrate species so far investigated, retinal melatonin is produced during darkness as is the 271 case in the pineal organ. However, teleost fish appeared to behave differently. Indeed, a 272 nocturnal retinal melatonin pattern, as seen in zebrafish and goldfish (Cahill et al., 1991; 273 Cahill, 1996; Iigo et al., 1997a), is not the general rule. In other species either no rhythm is 274 detected, or the peak is seen at different times of the LD cycle, including day (Gern et al., 1978; Besseau et al., 2006; Iigo et al., 1997b; Migaud et al., unpublished). In the sea bass, the 276 phase of the retinal rhythm changed throughout seasons (Bayarri et al., 2003). These 277 differences in the retinal patterns may be due to the fact that several retinal cell types 278 (including photoreceptors, inter-neurons and ganglion cells) express the melatonin biosynthesis enzymes AANAT and HIOMT (Besseau et al., 2006; Vuilleumier et al., 2007). It is not known yet (i) to which extent these cell types contribute to the overall retinal melatonin content and (ii) if melatonin production by these cells is under photoperiodic 282 control. In this regard it is interesting that non-visual photoreceptors have been identified in 283 the inner nuclear and ganglion cell layers of the fish retina (Cahill and Besharse 1995; Foster and Bellingham 2004; Bellingham et al., 2006). Thus, the photoperiodic control of melatonin production would not be exclusive to photoreceptor cells as believed for long. Another explanation for the retinal/pineal differences may result from this unique feature of teleost 287 fish, which express one or two AANAT1 (1a, 1b) genes in the retina (Begay et al., 1998; 288 Falcon et al., 2003; Tosini and Fukuhara, 2003; Coon and Klein, 2006). Irrespective of these differences, the production by the retina is under circadian clock control in some but not all species (Iuvone et al., 2005), as is the case in the pineal organ. 


\subsection{Plasma and cerebrospinal fluid (CSF) melatonin is from the pineal organ?}

293

294

295

296

297

298

299

300

301

302

303

304

305

306

307

308

309

310

311

312

The plasma melatonin rhythm shows a nocturnal surge. In higher vertebrates, it was shown that melatonin produced by the pineal gland is directly released into the CSF through the pineal recess resulting in CSF levels twenty times as high as in the blood (Tricoire et al., 2002). However, because there are several sources of melatonin in the organism (retina, pineal gland, intestine; Bubenik et al., 1997), this raises the question of knowing to which extend each of these organs contributes to the plasma and CSF levels. The question is even more relevant in species where retinal and pineal melatonin rhythms are not in phase. Early studies have shown that pinealectomized fish loose the plasma melatonin rhythm, indicating the pineal organ is the main source of plasma melatonin. The presence of a strong melatonin deacetylase activity in retinal tissues of non mammalian vertebrates, including fish (Grace et al., 1991), prevents melatonin from being released into the blood stream and conversely, of melatonin from other sources to reach the retina. It is believed that the main role of retinal melatonin is to serve local functions, including retinomotor movements, modulation of neurotransmitter release or neuronal electrical activity (Besseau et al., 2006; Siu et al., 2006; Ping et al., 2008; Sauzet et al., 2008). It is interesting that the retinal cells that express the melatonin biosynthesis enzymes also express the melatonin receptors, further supporting the idea of melatonin being an autocrine signal in the retina (Sauzet et al., 2008). In brief, although non pineal tissues may contribute to the blood plasma levels, the circulating melatonin levels reflect mainly the activity of the pineal organ circadian clocks synchronized by the LD cycle.

\subsection{Extra-pineal and extra-retinal sources of melatonin in the fish brain?}


Since the initial studies by von Frisch (1911) and Benoit (1935), morpho-functional

318 evidence has accumulated indicating the existence of a non-pineal, non-retinal

319 photosensitivity in the central nervous system. First, light penetrates deep into the brain

320 (Foster and Hankins 2002; Vigh et al., 2002b). Second, ophthalmectomized / pinealectomized

321 fish still responded to photoperiodic stimuli (Davis et al., 1986; Garg 1989; Day and Taylor

322 2005; Masuda et al., 2005). Third, electrical recordings from non-pineal non-retinal origin

323 have been obtained from frog diencephalon and mesencephalon (Cadusseau and Galand,

324 1980, 1981). Fourth, components of the phototransduction cascade, including opsin and $\alpha$ -

325 transducin have been detected in discrete brain areas of lampreys, fish, frogs and lizards

326 (Foster et al., 1994; Yoshikawa et al., 1994; Garcia-Fernandez et al., 1997; Okano et al.,

327 2000; Philp et al., 2000a, b; Àlvarez-Viejo et al., 2004). These areas include ependymal cells

328 that border the third ventricle as well as cells located in the SCN and preoptic area (POA).

329 Because the pineal and retinal photoreceptors are cellular circadian systems, it is tempting to

330 speculate that all the photoreceptive cells of the fish organism possess a molecular clock.

331 Indeed, studies in the lizard Podarsis sicula have shown that blockage of opsin expression in

332 the cells bordering the III $^{\text {rd }}$ ventricle abolished circadian entrainment in pinealectomized and

333 eyectomized lizards (Pasqualetti et al., 2003). In zebrafish, clocks have been identified in

334 several extra-retinal/extra-pineal tissues, including brain, liver and heart (Cahill 1996; Cahill

335 1997; Kazimi and Cahill 1999; Whitmore et al., 1999; Cahill 2002; Dekens et al., 2003;

336 Vallone et al., 2005). Thus, the circadian organization of non mammalian vertebrates, 337 including fish, might consist of a network of more or less powerful interconnected circadian 338 oscillators, located in distinct areas (Fig. 1). This is supported by previous findings showing 339 that pinealectomy induces species-dependent effects on the circadian activity rhythm of fish 340 and lizards (Kavalier, 1989), resulting in either (i) complete loss of circadian activity rhythm,

341 (ii) change of circadian period or (iii) splitting of the circadian rhythm into several 
components. In other words, the pineal organ is a 'mandatory' component or just a more or

343 less powerful element in the circadian network.

The demonstration that diencephalic cells of Rana perezi (including SCN cells)

345 express Aanat 1 adds to this puzzling picture and leads to the tempting hypothesis that some

346 parts of the brain concentrate photosensitivity, circadian clock function and entrainment of

347 AANAT gene expression. The functional significance of Aanat expression in the brain is yet

348 to be discovered. Kinetic studies indicated AANAT1 may catalyse the acetylation of both 349 dopamine and serotonin, leading to the formation of acetyl derivates, with specific functions 350 in the brain (Zilberman-Peled et al., 2006). Another possibility would be that these cells also 351 produce melatonin; preliminary investigations suggested this could be the case.

\subsection{Conclusions}

In brief, there is extensive evidence demonstrating the complexity of the light perception system in fish which involves the 'conventional' photoreceptive organs (retina, pineal) as well as most probably deep brain photoreceptors, the nature of which awaits further 358 characterization. The organization of the circadian system has changed dramatically during evolution. Obviously, the mammalian and teleost fish arms have followed different evolution

360 patterns, the modalities of which are far from being understood. It is interesting that the 361 system in some fish has features displaying resemblance with the mammalian system (Migaud 362 et al., 2007). More information is needed in order to determine whether this reflects a 363 convergent evolutionary trend between teleost fish and tetrapods. The coexistence of several 364 circadian systems in teleost fish raises a number of questions relative to their respective roles and synchronization. 
3. THE PINEAL TARGETS

\subsection{The targets of the nervous message}

The pineal organ exhibits bidirectional connections with the brain through pinealofugal (efferent) and pinealopetal (afferent) projections. These connections have been elucidated in different fish classes including agnatha (lampreys), Chondrichtyes and teleosts using anterograde and retrograde tract-tracing markers such as horseradish peroxidase, lysinecobalt and DiI (Ekström et al., 1984; Jiménez et al., 1995; Yáñez and Anadón, 1998; Pombal et al., 1999; Mandado et al., 2001). Pinealofugal projections can be considered as neural 378 outputs conveying photic information to the central nervous system. These studies have revealed the existence of an efferent tract that exits the pineal stalk to reach a number of structures including the habenula, ventral and dorsal thalamus, posterior commissure, periventricular pretectum, pretectal area, posterior tuberculum, paraventricular organ,

382 posterior tuberal nucleus, dorsal synencephalon and tegmentum (Fig. 5). A controversy exists 383 concerning the presence of pinealofugal terminal fields in the POA/anterior hypothalamus 384 (SCN?), which is also a retino-recipient area. Terminal projections have been detected in the Atlantic salmon, goldfish, sole, sturgeon and skate (Confente and Muñoz-Cueto, unpublished; Holmqvist et al., 1992; Jiménez et al., 1995; Mandado et al., 2001; Yañez and Anadón, 387 1998), but not in dogfish, lamprey, rainbow trout, stickleback, eel, carp and sea bass 388 (Ekström,1984; Ekström and van Veen, 1984; Hafeez and Zerihun, 1974; Mandado et al., 2001; Servili et al., 2005; Yáñez et al. 1993). The functional significance of the pinealofugal innervations remains enigmatic. The fish pineal organ also receives axon terminals originating

391 from cells in the thalamic eminentia, habenula, dorsal thalamus, ventromedial thalamus, 
periventricular pretectum, posterior commissure, posterior tuberculum and dorsal 393 synencephalon (Ekström et al., 1994; Jiménez et al., 1995; Yáñez and Anadón, 1998; Pombal

394 et al., 1999; Mandado et al., 2001; Servili et al., 2005). Some of these brain areas overlap 395 with brain regions that also appear connected with the retina (ventral and dorsal thalamus, 396 pretectal area, posterior tuberculum), revealing their importance in the integration of 397 photoperiod information, and constituting a possible pathway for the exchange of information 398 between the retina and pineal organ.

\subsection{The targets of the hormonal message}

401

Melatonin represents the main hormonal output of the pineal organ. Its involvement in the control of processes displaying daily or seasonal rhythms is widely accepted but not fully demonstrated yet. In fish, daily rhythms affected by the pineal organ and/or melatonin include locomotors activity, thermal preference, rest, food intake, vertical migration and shoaling, skin pigmentation, osmoregulation and metabolisms (including control of hypothalamic 407 monoamines, hepatic lipids and glucose and plasma steroid levels); annual processes include 408 smoltification (for migrating salmonids), growth and reproduction (Falcón et al., 2007). 409 Studies that aimed at elucidating the role melatonin plays in fish first used photoperiod 410 manipulations, pinealectomy or melatonin administration, however the responses to these 411 treatments was variable as they were dependent on too many factors as discussed elsewhere 412 (Mayer et al., 1997). Another strategy is to identify and characterize the melatonin receptors, 413 and localize there sites of expression, from where it will be possible to investigate what 414 functions they modulate and how. 
In fish the cloning and pharmaco-kinetic experiments using $2-\left[{ }^{125} \mathrm{I}\right]$-iodomelatonin

$418\left({ }^{125} \mathrm{IMel}\right)$ have allowed the identification of three high affinity melatonin receptor subtypes,

419 all belonging to the family of G-protein coupled seven transmembrane domains receptors, the

420 MT1, MT2 and Mel1c (Falcón et al., 2007). Studies conducted mainly in mammals indicated

421 that the melatonin receptors may be coupled to several intracellular pathways, the more

422 common being the adenyl cyclase/cyclic AMP (cAMP) and the pholspholipase

$423 \mathrm{C} /$ diacyglycerol/inositol tri-phosphates, pathways (Falcón et al., 2007). The full length

424 cloning of the melatonin receptors has been obtained in trout (MT1), rabbitfish (MT1, Mel1c),

425 seabass (MT1, MT2, Mel1c), sole (MT1, MT2, Mel1c) and pike (MT2) (Sauzet et al., 2008

426 and unpublished). More full length sequences predicted from the genome analysis of 427 zebrafish, tetraodon (T. biocellatus) and fugu (Sphoeroides maculatus), are available from the 428 databases. Functional studies indicated the fish MT2 receptor is negatively coupled to the cAMP pathway.

\subsubsection{Tissue specific expression of the melatonin receptors}

Fish MT1 and MT2 receptors are widely distributed in the nervous (retina, brain) and peripheral tissues, whereas Mellc expression is mainly found in the skin and retina (Falcón et al., 2007; Sauzet et al., 2008).

$\underline{\text { Brain and pituitary }}$

In the brain of lampreys, Chondrichtyes and Teleost fish, gene expression or ${ }^{125} \mathrm{IMel}$

437 binding are associated with areas that receive or integrate information from sensory organs 438 (e.g., olfactive bulbs, telencephalon, diencephalon, optic tectum and cerebellum) and the 439 receptors are mostly associated with areas receiving input from the retina and/or the pineal.

440 Melatonin serves as yet unknown functions in the central nervous system of fish. However, it 441 is noteworthy that fish diencephalic areas that bind melatonin may also express molecules of 
442 the visual cascade (e.g., opsins, transducin, arrestin) and receive nervous input from the eye or 443 the pineal or both (Ekström and Meissl, 1997; Alvarez-Viejo et al., 2004; Philp et al., $4442000 \mathrm{a}, \mathrm{b})$. This could suggest melatonin might well be the 'conductor' that phases photoperiod 445 related activities in a network of players (Fig. 1). Because, as suggested above, melatonin 446 might be synthesized locally, it could also be an autocrine regulator in these areas, as it 447 appears to be the case in the retina.

448 In addition, expression, binding and pharmacological studies have demonstrated that 449 melatonin receptors linked to inhibition of cAMP are present in the pituitary gland of pike, 450 trout and seabass (Gaildrat et al., 2002; Falcón et al., 2003, Sauzet et al., 2008).

$451 \quad$ Retina

452 Retinal melatonin is involved in the control of a number of retinal functions, including 453 melanosome aggregation in the pigment epithelium, rod outer segment shedding, cone 454 retinomotor movements, modulation of neurotransmitters release and electroretinogram 455 (Lundmark et al., 2006; O'Brien and Klein, 1986; Pautler and Hall, 1987). A recent study in 456 the seabass identified MT1 and MT2 expression in the three nuclear layers of the neural fish 457 retina (as is the case in other vertebrates) as well as in the retinal pigment epithelium (Sauzet 458 et al., 2008). It is interesting that in the neuronal retina, the receptors are expressed in the 459 same cell types that also express the melatonin biosynthesis enzymes, which indicates 460 melatonin is a true autocrine regulator in this organ.

Peripheral tissues

462 Expression of melatonin receptors or ${ }^{125} \mathrm{IMel}$ binding, have been detected in different 463 peripheral tissues, including kidney, intestine, blood cells, gonads and gills (Kulczykowska et 464 al., 2006; Park et al., 2006; Sauzet et al., 2008, and authors' unpublished data). The functional 465 significance of these receptors awaits further experimentation. 


\subsection{The photoneuroendocrine connexions in fish}

468

469

470

471

472

473

474

475

476

477

478

479

480

481

482

483

484

485

486

487

488

489

490

491

The photic information can reach the pituitary directly through its hormonal messenger melatonin and pituitary melatonin receptors, as mentioned above. Upstream to the pituitary, at least four diencephalic areas appear as key components: the POA, SCN, lateral tuberal nucleus (LTN) and ventromedial thalamic nucleus (VTN). All four receive hormonal information (Ekström and Vanecek, 1992; Vernadakis et al., 1998; Herrera-Perez et al., 2007; Sébert et al., 2008), and some receive nervous information as well, from either the retina (POA, SCN) or the pineal organ (POA, VTN) (Ekström and Meiss1, 1997; Mandado et al., 2001). In turn, POA and hypothalamic neurons send projections to the pituitary; dopamine and peptides released from these terminals regulate pituitary function (Batten et al., 1993, 1999; Cerdá-Reverter et al., 1999, 2000; Chiba, 1999; Kah et al., 1993; García-Robledo and Muñoz-Cueto, unpublished). The latter include pituitary adenylate cyclase activating peptide (PACAP), Neuropeptide Y (NPY), growth hormone-releasing hormone (GHRH), corticotrophin-releasing hormone $(\mathrm{CRH})$ and gonadotropin-releasing hormones (GnRHs) (Batten et al., 1999; Montero et al., 2000; González-Martinez et al., 2002).

There is also indication that POA and hypothalamic neurons may impact on the light sensitive organs. This includes GnRH neurons that innervate both the retina and the pineal organ (Gonzalez-Martinez et al., 2004; Sakharkar et al., 2005; Servili et al., 2007; WirsigWiechmann and Wiechmann, 2002), NPY and GHRH neurons that innervate the pineal (Blank et al., 1997; Subhedar et al., 1996). Of course the list is most certainly not exhaustive.

\section{MELATONIN EFFECTS}


493 and/or melatonin treatment led to conflicting conclusions regarding the role melatonin plays

494 in neuroendocrine regulations (Mayer et al., 1997; Bromage et al., 2001; Boeuf and Falcón, 495 2002; Falcón et al., 2007). This is because these studies used different experimental 496 procedures (the time of the year at which the experiments were done was crucial), different 497 species or, within a same species, animals of different sex and historical status. However, 498 evidence is now coming to light which indicates melatonin mediates the effects of 499 photoperiod on several neuroendocrine functions.

\subsection{Reproduction}

The impact of melatonin on the seasonal cycle of reproduction has been largely investigated using photoperiod manipulations, pinealectomy and/or melatonin administration (Ekström an Meissl, 1997; Mayer et al., 1997). But the first unequivocal evidence that melatonin has indeed an effect came from an in vitro study in the Atlantic croaker (Micropogonias undulatus) (Khan and Thomas, 1996). In fish with fully developed gonads, low

508 concentrations of melatonin stimulated in vitro LH release from pituitary cells in culture; in vivo, melatonin elicited significant elevations in plasma LH levels late during the photophase of the day-night cycle, when administered in the basal diencephalon. This suggested that

511 melatonin acted both at the POA/hypothalamus and pituitary levels. This was recently

512 confirmed in the eel where melatonin implants induced a decrease in LH $\beta$ and FSH $\beta$ 513 expressions as well as in plasma levels of some sexual steroids (Sébert et al., 2008). This was 514 partly achieved through an action on the POA dopaminergic cells, which were the only brain catecholaminergic cells showing increased tyrosine hydroxylase (TH) expression. However,

516 what applies to eels might not be the rule for other fish. In cultured carp hypothalamus, 
melatonin reduces dopamine levels, which would result in an increased LH $\beta$ secretion (Popek

518 et al., 2005). Further evidence that melatonin plays a significant role in the regulation of annual testicular events was obtained in a sub-tropical fish species, carp, Catla catla

520 (Bhattacharya et al., 2007). Indeed, the authors of this study showed precocious testicular

521 maturation in both melatonin-treated fish and fish exposed to continuous darkness (DD)

522 during the preparatory phase and an inhibition of testicular function during the pre-spawning 523 and spawning phases. Results obtained by the same group also recently demonstrated that 524 melatonin can accelerate the action of the Maturational Inducting Hormone (MIH) when 525 added $4 \mathrm{~h}$ prior to MIH in the incubation medium (Chattoraj et al., 2005) and that serotonin 526 inhibits the actions of MIH, but also the actions of melatonin on the MIH-induced oocyte 527 maturation in carp (Chattoraj et al., 2008).

\subsection{Growth and feeding}

Available data indicate fish growth follows a seasonal pattern which varies as a

532 function of day-length (Boeuf and Falcón, 2002). Generally, larvae need a minimal light intensity threshold to be able to develop and grow normally. Older fish (marine and salmonid species) also react to photoperiod manipulations; long days generally stimulate growth in diurnal fish species. The synergistic effect of "food availability" and "day length" is

536 important. Growth, food intake and digestion are related to specific behavioural rhythms and

537 to reproduction; and, a pineal (melatonin) control is thought to operate here (Ekström and 538 Meiss1, 1997; Mayer, 2000; Porter et al., 1998; Underwood, 1989; 1999; Zachmann et al., 539 1992; Zhdanova et al., 2001). However, the results are often contradictory. For example, (i) 540 i.p. administration of melatonin to goldfish maintained under short - but not long 541 photoperiod for several days accelerated weight gain and growth (De Vlaming, 1980); (ii) 
melatonin implants increased weight in Atlantic salmon parr (Salmo salar; Porter et al., 1998)

543 but reduced body weight and growth rate in trout (Oncorhynchus mykiss; Taylor et al., 2005).

544 Regarding feeding, it has been shown that acute melatonin treatments generally result in a

545 reduced food intake (De Pedro et al., 2008; Lopez-Olmeda et al., 2006; Pinillos et al., 2001;

546 Rubio et al., 2004); but, fish grow differently depending on the circadian time feeding

547 (Spieler, 2001). Overall, these discrepancies might just reflect a seasonal regulation of feeding

548 and growth. It has been shown that in vitro, cultured trout pituitary glands or cells released

549 increasing levels of GH when challenged with physiological concentrations of melatonin

550 (Falcón et al., 2003). However, inhibition of GH release was also observed under specific

551 pharmacological conditions, suggesting a bimodal effect of melatonin on GH production.

552 And, under conditions that stimulate GH secretion, melatonin also induced a sustained

553 inhibition of PRL release (Falcón et al., 2003). GH and PRL are two closely related hormones

554 that often act in an antagonistic manner (Nguyen et al., 2008). The effects of melatonin on

555 growth may thus result from the differential impact the hormone has on GH and PRL, and

556 perhaps on other pituitary hormones. In addition to a direct effect on the pituitary, melatonin

557 might also modulate fish feeding and growth through controlling the production of releasing

558 and inhibiting factors by neurons from the POA and hypothalamic nuclei (see above) as well

559 as by targeting directly peripheral tissues. Thus, in the goldfish melatonin administration (i)

560 inhibited food intake, but only after i.p., not intra-cerebral administration, excluding a

561 centrally-mediated action (Pinillos et al., 2001), and (ii) reduced body weight gain and

562 specific growth rate through modulating noradrenergic metabolism in the hypothalamus (De

563 Pedro et al., 2008).

\subsection{Immune system}


It is well documented that seasonality affects the immune response of vertebrates

568 (Zapata, 1992). In fish, adaptive immunity exhibits a seasonal cycle. This includes changes in resting antibody titer and response to antigenic challenge (Nakanishi, 1986), lymphoid system (Álvarez et al., 1998; Wojtowicz and Plytycz, 1997), number of circulating lymphocytes (Slater and Schreck, 1998), lysozyme activity and number of red and white blood cells

572 (Morgan et al., in press). The involvement of the pineal organ and melatonin in the control of 573 immunity remains to be clarified. But preliminary investigations in trout and sea bass indicate melatonin affects the expression of genes such as PRL, GH or proopiomelanocortin (POMC) (Falcón et al., 2001, and unpublished). GH and PRL are involved in the control of immunity in fish; and, the POMC gene encodes a protein precursor of active peptides including $\alpha$ - and $\beta$-melanocyte stimulating hormone, corticotropin hormone (ACTH), lipoprotein hormone and $\beta$-endorphine, which are involved in the control of stress, feeding and immunity.

\subsection{Conclusions}

In brief, although investigations on the relationships between the pineal organ and melatonin on the one hand, and the neuroendocrine system on the other hand, are just at their beginnings, it seems more and more evident that the time-keeping hormone impacts directly or indirectly on the production of pituitary hormones, thus affecting time regulated functions, including feeding, growth, reproduction and immunity. More studies are necessary to unravel

587 the regulatory processes activated by melatonin on a daily and annual basis. Such investigations have great potential interest for the aquaculture industry.

\section{IMPLICATIONS FOR AQUACULTURE}


594 rhythms and how they are synchronized and entrained in teleost is a black box despite its

595 importance for aquaculture. Fish reproductive physiology shows an extraordinary close 596 adaptation to the cyclical variations of the environment; fish synchronize their spawning to 597 the period of the year most favorable for the survival of progeny. Accordingly, fish have 598 developed predictive mechanisms using photoperiod as a reliable environmental cue 599 (proximal factor) to anticipate and activate gametogenesis long before spawning (Carrillo et al. 1993; Bromage et al. 2001). The period of reproduction of most temperate commercial 601 fish species important for aquaculture is restricted to only a few months of the year, when the 602 most appropriate environmental conditions are found; this guarantees the best chances of 603 progeny survival. However, the restriction of reproductive activity to a short annual window 604 is a problem for fish farmers that rely on year long supply of juveniles to satisfy an increasing 605 demand in fish. Early maturation during on growing is another major bottleneck leading to 606 losses due to deterioration of flesh quality, external appearance and poor growth 607 performances. Consequently, based on the basic understanding of the circadian axis and 608 photoperiodic entrainment of reproduction, regimes have been developed with great success to manipulate the natural circannual rhythm of spawning in many temperate fish species.

610 Importantly, photoperiod could also be used to improve reproductive performances in tropical

611 fish species although these species do not experience significant annual photoperiodic 612 changes in their natural habitat (Campos Mendoza et al., 2004).

613

\section{5.1. Photic manipulation of fish physiology}


season is used throughout the industry to manipulate the timing of broodstock spawning,

618 smoltification and early maturation in a number of commercially important species (salmon,

619 trout, cod, sea bass, halibut....). Compression or extension of the seasonal light cycle results

620 in spawning advance or delay, respectively, in salmonid species (Bromage and Duston, 1986;

621 Bromage et al., 2001). Similarly, the time of first sexual maturation can also be modified by

622 photoperiod manipulations in teleosts (Randall et al., 1998; Rodríguez et al., 2001). In

623 salmonids, it is now evident that the increasing and decreasing components of the seasonally changing day-length are responsible for the recruitment of fish into reproduction and gonadogenesis, respectively (Endal et al., 2000; Bromage et al., 2001). This is in contrast with findings in Atlantic cod (Gadus morhua) showing a phase shift control of reproduction with decreasing day-length recruiting individuals into reproduction and increasing day-length

628 stimulating gonadogenesis (Hansen et al., 2001; Davie et al., 2007a,b). However, these increasing and decreasing photoperiods can also be replaced by periods of constant day-length (Carrillo et al., 1993; Bromage et al., 2001). Interestingly, continuous light can also fully inhibit reproduction in cod (Davie et al., 2007a) and prevent precocity in juvenile male sea

632 bass (Begtashi et al., 2004). This is routinely used in fish farming especially to suppress or 633 decrease early maturation during the growth phase. For this purpose, continuous artificial 634 lighting is applied from either winter solstice in salmon or summer solstice in cod with the aim to trick the fish in believing that they are in summer (salmon) during the winter time or mask the autumnal decrease in daylength (cod). Continuous light treatments (LL) given either

637 at the pregametogenesis or during the gametogenesis to juvenile male sea bass were equally 638 effective in reducing the number of early maturing males suggesting light may have a direct 639 effect on the arrest of meiotic divisions of the germinal cells and thus on the gonadogenesis 640 (Felip et al., 2008). Besides, this work indicated that a potential photo-labile period may exist 641 in the sea bass located somewhere in the autumn between September and October. The recent 
642 location of such a photo-labile period (Fig. 6; Carrillo et al., 2008) offers the possibility to

643 effectively suppress early maturation in sea bass by a two months exposure to continuous 644 light in otherwise natural photoperiod, reducing considerably the duration of the treatment 645 with equal effectiveness than the longer ones.

646 Bayarri et al., (2008) demonstrated that the presence of a photoperiod is necessary to 647 maintain the circadian variations in certain reproductive hormones, which are, at the same 648 time, necessary for the normal process of reproduction. However, when LL is applied and 649 suppression of daily rhythms of key hormones such as melatonin and LH in fish is produced, 650 gonadal development and maturation becomes full arrested (Fig. 7).

Light is also used in the salmon industry to manipulate the timing of smoltification by 652 using short day winter photoperiods in summer (Duston and Saunders 1992). A combination 653 of constant 1-3 months duration long days, in otherwise constant short days, applied at different times of the year followed by an appropriate thermal manipulation has been proved to be a reliable tool to obtain spawns every month of the year in some sea bass farms of the Mediterranean area (Carrillo et al., 1995; Carrillo, unpublished results).

\subsection{Light sensitivity}

659

One major question concerning light manipulation in fish farming relates to the 661 duration and quality of the photic signal (Bromage et al., 2001; Boeuf and Falcón 2002). 662 Duration varies along the annual cycle in a regular and predictable manner, whereas quality 663 varies in a less predictable manner. Thus, in order to optimize the rearing conditions and 664 eventually being able to manipulate the fish physiology one has to consider the respective 665 durations of day and night and, in both situations, light intensity, spectral composition and orientation. It is important to emphasize that fish perceive light both from above (via the 
667 pineal organ), the sides (via the eyes) and possibly through deep brain photoreceptors. In 668 addition, it is evident that the intensity and quality of light that reaches the pineal organ and 669 brain depends on the degree of absorbance through the skin and skull. The amount and quality 670 of light that crosses the pineal window varies from one species to another (Gern et al., 1992; 671 Migaud et al., 2006, 2007). Differences in light penetration through the skull range from 1 to $6728 \%$ of simulated daylight in Teleost fish; and, long wavelengths $(650-700 \mathrm{~nm})$ are far more 673 effective at penetrating the skull than shorter wavelengths $(400-450 \mathrm{~nm})$. For example, in 674 terms of melatonin production the threshold of light intensity above which melatonin is 675 suppressed depends on the species, experimental conditions (in vitro or in vivo), light quality 676 and duration (Aoki et al.,, 1998; Bayarri et al.,, 2002; Migaud et al., 2006 and unpublished; 677 Oliveira et al., 2007; Vera et al., 2005). It depends also on the developmental stage/size of the 678 fish, temperature profiles and previously experienced photic conditions. All these factors 679 highlight the difficulties generally encountered when attempting to compare and review 680 existing data in fish.

\subsection{Circannual Rhythms and the Endogenous Control of Reproduction}

683

684

685

686

687

The demonstration that the seasonal cycle of reproduction is controlled by a time keeping system requires long term and costly studies. An endogenous clock controlled rhythm must satisfy a number of criteria in order to be defined as such. It should be observed for at least 2 full cycles and with a period that approximates 12 months under constant conditions; it should also be entrained by an environmental zeitgeber (e.g., photoperiod) and display temperature compensation (Gwinner, 1986). The demonstration that a circannual endogenous mechanism controls reproduction is of paramount importance to fully understand reproductive physiology and eventually elaborate species depend strategies to optimize either growth or 
692

693

694

695

696

697

698

699

700

701

702

703

704

705

706

707

708

709

710

711

712

713

714

715

716

reproduction. An endogenous control of reproduction has been reported in many species of fish, in animals maintained under constant conditions of photoperiod, temperature, salinity, etc... These include trout (Bromage et al., 1984; Duston and Bromage, 1991; Randall et al 1999), stinging catfish, Heteropneustes fossilis (Sundararaj et al., 1982), three-spined stickleback, Gasterosteus aculeatus (Baggerman, 1980), sea bass, Dicentrarchus labrax (Carrillo et al., 1993, Prat et al., 1999); Barbel, Barbus barbus (Poncin 1991) and Atlantic halibut, Hippoglossus hippoglossus (Björnsson et al., 1998). A better understanding of these circannual rhythms can help to improve broodstock management within the aquaculture industry.

\section{CONCLUSIONS}

It is widely accepted that melatonin is a much conserved feature that plays a central role in the entrainment of daily and annual physiological rhythms in vertebrates. Over the last decades, a large amount of research has been carried out in fish, especially teleosts, to unravel the puzzling roles of melatonin in fish and characterize inter-species differences. As a result, the picture is becoming much clearer with regards to the control of the melatonin synthesis (limiting enzyme AANAT, connection/projection...) and the identification of target tissues, neurons and cells (melatonin receptor expression and localisation). However, the multiple and complex effects of melatonin on fish neuroendocrine regulation still awaits a more complete and precise understanding. Indeed, to date, although fish seasonality and photoperiodism has been demonstrated in many fish species, only few direct evidences exists on how melatonin acts on the Brain-Pituitary-Gonadal axis controlling reproduction, the somatotropic axis controlling appetite, feed intake and growth, and behaviour, just to name a few examples, in 
717 fish. With the recent "post-genomic" advances, it will now be feasible to identify and

718 characterize patterns of gene expression among the suite of genes that control circadian

719 rhythms and link them to physiological processes. Such a broad-view transcriptomics

720 approach is particularly appropriate for addressing basic questions concerning co-ordination

721 of activities within complex functional networks such as the melatonin system. One major

722 constraint that fish biologist have to address is the multitude of adaptations/organisations that

723 can be found in fish in contrast to mammals meaning that no generalized fish model can be easily drawn. On the other hand, this can also be considered as a strength as comparative studies within fish species can help to better understand evolutionary trends that have led to

726 the situation observed in mammals. Importantly, the study of the circadian axis and melatonin

727 is very relevant to the aquaculture industry. The large variability in regulatory systems,

728 sensitivities and responses observed among Teleosts means that species specific regimes will

729 have to be implemented in commercial set ups to improve and standardized husbandry

730 practices (use of light, handling, broodstock management, vaccination...) in fish aquaculture.

731 To do so, a better understanding and characterisation of circadian and circannual rhythms is

732 clearly needed. 
736 Alvarez, F., Razquin, B.E., Villena, A.J., Zapata, A.G.., 1998. Seasonal changes in the lymphoid organs of wild trout, Salmo trutta L.: a morphological study. Vet. Immunology Immunopathol. 64, 267-78.

Alvarez-Viejo, M., Cernuda-Cernuda, R., Alvarez-López, C., García-Fernández, J.M., 2004. Identification of extraretinal photoreceptors in the teleost Phoxinus phoxinus. Histol

Appelbaum, L., Toyama, R., Dawid, I.B., Klein, D.C., Baler, R., Gothilf, Y., 2004. Zebrafish serotonin- $N$-acetyltransferase-2 gene regulation: Pineal-restrictive downstream module (PRDM) contains a functional E-box and three photoreceptor conserved elements. Mol. Endocrinol. 18, 1210-1221.

Appelbaum, L, Gothilf, Y., 2006. Mechanism of pineal-specific gene expression: The role of E-box and photoreceptor conserved elements. Mol. Cell. Endocrinol. 252, 27-33.

Baggerman, B. 1980. Photoperiodic and endogenous control of the annual reproductive cycle in in teleost fishes. pp. 553-568. In: Environmental Physiology of fishes edited by M.A.

Batten, T.F., Berry, P.A., Maqbool, A., Moons, L., Vandesande, F., 1993. Immunolocalization of catecholamine enzymes, serotonin, dopamine and L-dopa in the brain of Dicentrarchus labrax (Teleostei). Brain Res. Bull. 31, 233-252.

Batten, T.F., Moons, L., Vandesande, F., 1999. Innervation and control of the adenohypophysis by hypothalamic peptidergic neurons in teleost fishes: EM immunohistochemical evidence. Microsc. Res. Tech. 44, 19-35. 
760 Bayarri, M.J., Rol de Lama, M.A., Madrid, J.A., Sanchez-Vazquez, F.J., 2003. Both Pineal and Lateral Eyes Are Needed to Sustain Daily Circulating Melatonin Rhythms in Sea Bass. Brain Res. 969, 175-182.

763

Bayarri, M.J., Zanuy, S., Yilmaz, O., Carrillo, M., 2008. Effects of continuous light on the reproductive system of European sea bass as gauged by alterations of circadian variations during their first reproductive cycle. Chronobiology International (In press).

Begay, V., Falcon, J., Cahill, G.M., Klein, D.C. and Coon, S.L., 1998. Transcripts encoding two melatonin synthesis enzymes in the teleost pineal organ: circadian regulation in pike and zebrafish, but not in trout. Endocrinol. 139, 905-912.

Begtashi, I., Rodríguez, L., Moles, G., Zanuy, S. and Carrillo, M., 2004. Long-term exposure to continuous light inhibits precocity in juvenile male European sea bass (Dicentrarchus labrax, L.). I. Morphological aspects. Aquaculture 241:539-559.

Bellingham, J., Chaurasia S.S., Melyan Z., Liu C., Cameron M.A., Tarttelin, E.E. Iuvone P.M., Hankins M.W., Tosini G. and Lucas R.J., 2006. Evolution of melanopsin photoreceptors: discovery and characterization of a new melanopsin in nonmammalian vertebrates, PLoS Biol. 4, p. 254.

Benoit, J., 1935. Stimulation par la lumiere du developpement testiculaire chez des canards aveugles par enucleation des globes oculaires. C.R. Soc. Biol. 120, 136-139.

Benyassi, A., Schwartz, C., Coon, S. L., Klein, D. C. and Falcón, J., 2000. Melatonin Synthesis: Arylalkylamine N-Acetyltransferases in Trout Retina and Pineal Organ Are Different. Neuroreport 11, 255-258.

Besseau, L., Benyassi, A., Moller, M., Coon, S.L., Weller, J.L., Boeuf, G., Klein, D.C., Falcón, J., 2006. Melatonin Pathway: Breaking the 'High-at-Night' Rule in Trout Retina. Exp. Eye Res. 82, 620-627. 
Bhattacharya, S., Chattoraj, A., Maitra, S.K., 2007. Melatonin in the Regulation of Annual Testicular Events in Carp Catla catla: Evidence from the Studies on the Effects of Exogenous Melatonin, Continuous Light, and Continuous Darkness. Chronobiol. Int.. 24, $629-650$.

Björnsson, B.T., Halldorsson, O., Haux, C., Norberg, B., Brown, C., 1998. Photoperiod control of sexual maturation of the Atlantic halibut (Hyppoglossus hippoglossus): plasma thyroid hormone and calcium levels. Aquaculture 166, 117-140.

Blank, H., Müller, B., Korf, H., 1997. Comparative investigations of the neuronal apparatus in the pineal organ and retina of the rainbow trout: immunocytochemical demonstration of neurofilament 200-kDa and neuropeptide Y, and tracing with DiI. Cell Tissue Res. 288, 417-425.

Boeuf, G., Falcón, J., 2001. Photoperiod and Growth in Fish. Vie Et Milieu-Life and Environment 51, 247-266.

Boeuf, G., Le Bail, P-Y., 1999. Does light have an influence on fish growth? Aquaculture $177,129-152$.

Bolliet, V., Ali, M.A., Lapointe, F.J., Falcón, J., 1996. Rhythmic Melatonin Secretion in Different Teleost Species: an in vitro Study. J. Comp. Physiol. B 165, 677-683.

Bradshaw, W. and Holzapfel, C., 2007. Evolution: Tantalizing timeless. Science 29, 18511852.

Bromage, N., Duston, J. 1986. The control of spawning in the rainbow trout (Salmo gardneri Richardson) using photoperiod techniques. Report of the Institute of Freshwater Research, Sweden. 63, 26-35.

Bromage, N., Porter, M., Randall, C., 2001. The environmental regulation of maturation in farmed finfish with special reference to the role of photoperiod and melatonin. Aquaculture 197, 63-98. 
809 Bromage, N.R., Elliott, J.A., Springate, J.R.C., Whitehead, C., 1984. The effects of constant 810 photoperiods on the timing of spawning in the rainbow trout. Aquaculture 43, 213-223.

811 Bubenik, G.A., Pang, S.F., 1997. Melatonin Levels in the Gastrointestinal Tissues of Fish, Amphibians, and a Reptile. Gen. Comp. Endocrinol. 106, 415-419.

813 Cadusseau, J., Galand, G., 1980. Electrophysiological evidence for white light sensitivity of 814 the encephalon in eyeless and pinealectomized frogs. Exp. Brain Res. 40, 339-341.

815 Cadusseau, J., Galand, G., 1981. Electrophysiological recordings of an extraocular and 816 extrapineal photo-reception in the frog encephalon. Brain Res. 219, 439-444.

817 Cahill, G.M., Grace, M.S. and Besharse, J.C., 1991. Rhythmic Regulation of Retinal 818 Melatonin: Metabolic Pathways, Neurochemical Mechanisms, and the Ocular Circadian Clock. Cell. Mol. Neurobiol. 11, 529-558.

820 Cahill, G.M., Besharse, J.C., 1995. Circadian rhythmicity in vertebrate retinas: regulation by a photoreceptor oscillator. Prog. Retin. Eye Res. 14, 267-291.

Cahill, G.M., 1996. Circadian Regulation of Melatonin Production in Cultured Zebrafish Pineal and Retina. Brain Research 708, 177-181.

824 Cahill, G.M., 1997. Circadian Melatonin Rhythms in Cultured Zebrafish Pineals Are Not 825 Affected by Catecholamine Receptor Agonists. Gen. Comp. Endocrinol. 105, 270-275.

826 Cahill, G., 2002. Clock mechanisms in zebrafish. Cell Tissue Res. 309, 27-34.

827 Campos-Mendoza, A., McAndrew, B.J., Coward. K., Bromage, N. 2004. Reproductive 828 response of Nile tilapia (Oreochromis niloticus) to photoperiodic manipulation; effects on 829 spawning periodicity, fecundity and egg size. Aquaculture 231, 299-314.

830 Carrillo, M., Zanuy, S., Prat, F., Serrano, R., Bromage, N.R., 1993. Environmental induction 831 of spawning in sea bass, pp. 43-54 in Recent advances in Aquaculture, vol 4, edited by R.J. Roberts and J. Muir. Blackwell Scientific publications, London. 
Carrillo, M., S. Zanuy, F. Prat, J. Cerdá, J. Ramos, E. Mañanós, and N. Bromage,1995. Sea bass, pp. 138-168 in Broodstock management and egg and larval quality, edited by N. R. Bromage and R. J. Roberts. Blackwell, Oxford.

Carrillo, M., Zanuy, S., Felip, A., Bayarri, M.J., Molés, G., Gómez, A., 2008. Hormonal and environmental control of puberty in perciform fish: the case of sea bass. Ann. N.Y. Acad. Sci. (in press).

Ceinos, R.M., Polakof, S., Illamola, A.R., Soengas, J.L., Míguez, J.M., 2008. Food deprivation and refeeding effects on pineal indoles metabolism and melatonin synthesis in the rainbow trout Oncorhynchus mykiss. Gen. Comp. Endocrinol. 156, 410-417.

Cerdá-Reverter, J.M., L.A. Sorbera, M. Carrillo, and S. Zanuy, 1999 Energetic dependence of NPY-induced LH secretion in a teleost fish (Dicentrarchus labrax). Am. J. Physiol. 277, $1627-1634$

Cerdá-Reverter, J.M., I. Anglade, G. Martinez-Rodriguez, D. Mazurais, J.A., Muñoz-Cueto, M. Carrillo, O. Kah, S. Zanuy, 2000. Characterization of neuropeptide Y expression in the brain of a perciform fish, the sea bass (Dicentrarchus labrax). J Chem. Neuroanat. 19, 197-210.

Chattoraj, A., Bhattacharya, S., Basu, D., Bhattacharya, S., Bhattacharya, S., Maitra, S.K., 2005. Melatonin accelerates maturation inducing hormone (MIH): induced oocyte maturation in Carps. Gen. Comp. Endocrinol. 140, 145-155.

Chattoraj, A., Seth, M., Maitra, S.K., 2008. Influence of serotonin on the action of melatonin in MIH-induced meiotic resumption in the oocytes of carp Catla catla. Comp. Biochem. Physiol A 150, 301-306.

Chiba, A., 1999. Immunohistochemical distribution of neuropeptide Y-related substance in the brain and hypophysis of the arctic lamprey, Lethenteron japonica. Brain Behav. Evol. $53,102-109$. 
858 Coon, S.L., Begay, V., Deurloo, D., Falcón, J., Klein, D.C., 1999. Two Arylalkylamine NAcetyltransferase Genes Mediate Melatonin Synthesis in Fish. J. Biol. Chem. 274, 90769082.

861

Coon, S.L., Klein, D.C., 2006. Evolution of Arylalkylamine N-Acetyltransferase: Emergence and Divergence. Mol. Cell. Endocrinol. 252, 2-10.

Davie, A., Porter, M., Bromage, N., Migaud, H. 2007a. The role of seasonally altering 864 photoperiod in regulating physiology in Atlantic cod (Gadus morhua). Part I. Sexual

Davie, A., Porter, M., Bromage, N., Migaud, H. 2007b. The role of seasonally altering photoperiod in regulating physiology in Atlantic cod (Gadus morhua). Part II. Somatic growth. Can. J. Fish. Aquatic Sc. 64(1), 98-112.

Davis, K.B., Goudie, C.A., Simco, B.A., MacGregor, R., Parker, N.C., 1986. Environmental Regulation and Influence of the Eyes and the Pineal Gland on the Gonadal Cycle and Spawning in Channel Catfish (Ictalurus punctatus). Physiol. Zool. 59, 717-724.

Day, J.R., Taylor, M.H., 2005. Environmental Control of the Annual Cycle of Fundulus heteroclitus L.: The pineal Organ and Eyes. J. Exp. Zool. 227, 453-458.

De Pedro, N., Martínez-Álvarez, R.M, Delgado, M.J., 2008. Melatonin reduces body weight in goldfish (Carassius auratus): effects on metabolic resources and some feeding regulators. J. Pineal Res. 45, 32-39.

De Vlaming, VL., 1980. Effect of pinealectomy and melatonin treatment on growth in the goldfish, Carassius auratus. Gen. Comp. Endocrinol. 40, 245-250.

Dekens, M.P.S., Santoriello, C., Vallone, D., Grassi, G., Whitmore, D., Foulkes, N.S., 2003. Light Regulates the Cell Cycle in Zebrafish. Current Biol. 13, 2051-2057. trout (Oncorhychus mylis). J. Biol. Rhythms 6, 49-53. 
883 Duston,„J., Saunders R.L., 1992. Effects of 6-,12-, and 18-month photoperiod cycles on

884

885

886

887

888

889

890

891

892

893

894

895

896

897

898

899

900

901

902

903

904

905

906

907 smolting and sexual maturation in juvenile Atlantic salmon (Salmo salar). Can. J. Fish. Aquatic Sc. 49, 2273-2280.

Ekström, P. 1984. Central neural connections of the pineal organ and retina in the teleost Gasterosteus aculeatus L. J. Comp. Neurol. 226, 321-335.

Ekström, P., Meissl H., 1997. The pineal organ of fishes. Rev. Fish Biol. Fisher. 7: 199-284.

Ekström, P. and J., Vanecek (1992) Localization of 2-[125I]iodomelatonin binding sites in the brain of the Atlantic salmon, Salmo salar L. Neuroendocrinol. 55, 529-537.

Ekström, P., van Vee,n T., 1984. Pineal neural connections with the brain in two teleosts, the Crucian carp and the European eel. J. Pineal Res. 1, 245-261.

Ekström, P., Meissl, H., 2003. Evolution of Photosensory Pineal Organs in New Light: the Fate of Neuroendocrine Receptors. Phil. Trans. R. Soc. Lond. B 358, 1679-1700.

Ekström, P., Östholm, T., Holmqvist, B.I., 1994. Primary visual projections and pineal neural connections in fishes, amphibians and reptiles. In M. Moller and P. Pévet (eds): Advances in Pineal Research: 8. London: John Libbey, pp. 1-18.

Endal, H.P., Taranger, G.L., Stefansson, S.O., Hansen, T., 2000. Effects of continuos additional light on growth and sexual maturity in Atlantic salmon, Salmo salar, reared in sea cages. Aquaculture 191, 337-349.

Falcón, J., Bolliet, V., Ravault, J.P., Chesneau, D., Ali, M.A., Collin, J.P., 1994. Rhythmic secretion of melatonin by the superfused pike pineal organ: thermo- and photoperiod interaction. Neuroendocrinology. 60: 535-543.

Falcón, J., Bolliet, V., Collin, J.P., 1996. Partial characterization of serotonin Nacetyltransferases from northern pike (Esox lucius\}, L.) pineal organ and retina. Effects of temperature. Pflügers Arch. 342, 386-396.

Falcón, J., 1999. Cellular circadian clocks in the pineal. Prog. Neurobiol. 8, 121-162. 
908 Falcón, J., Galarneau, K.M., Weller, J.L., Ron, B., Chen, G., Coon, S.L., Klein, D.C.. 2001. Regulation of arylalkylamine N-acetyltransferase-2 (AANAT2, EC 2.3.1.87) in the fish pineal organ: Evidence for a role of proteasomal proteolysis. Endocrinol. 142, 18041813.

Falcón, J., Gothilf, Y., Coon, S.L., Boeuf, G., Klein, D.C., 2003. Genetic, Temporal and Developmental Differences Between Melatonin Rhythm Generating Systems in the Teleost Fish Pineal Organ and Retina. J. Neuroendocrinol. 15, 378-382.

Falcón, J., Besseau, L., Sauzet, S., Bœuf, G., 2007a. Melatonin effects on the hypothalamopituitary axis in fish. Trends Endocrinol. Metab. 18, 81-88.

Falcón, J., Besseau, L., Sauzet, S., Boeuf, G., 2007b. Mélatonine et régulations neuroendocrines chez le poisson. J. Soc. Biol. 201, 21-29.

Felip, A., S. Zanuy, B. Muriach, J. M. Cerdá-Reverter, and M. Carrillo. 2008. Reduction of sexual maturation in male Dicentrarchus labrax bycontinuous light both before and during gametogenesis. Aquaculture 275:347-355

Foster, R.G., Hankins, M.W., 2002. Non-rod, non-cone photoreception in the vertebrates. Prog. Ret. Eye Res. 21 507-527.

Foster, R.G., Bellingham, J., 2004. Inner retinal photoreceptors (IRPs) in mammals and teleost fish. Photochem. Photobiol. Sci. 3, 617-627.

Foster, R.G., Grace, M.S., Provencio, I., Degrip, W.J., Garcia-Fernandez, J.M., 1994. Identification of vertebrate deep brain photoreceptors. Neurosci. Biobehav. Rev. 18, 541554.

Gaildrat, P., Becq, F., Falcón, J., 2002. First cloning and functional characterization of a melatonin receptor in fish brain: a novel one? J. Pineal. Res. 32, 74-84.

Garcia-Fernandez, J.M., Jimenez, A.J., Gonzalez, B., Pombal, M.A., Foster, R.G., 1997. An immunocytochemical study of encephalic photoreceptors in three species of lamprey. 
Cell Tissue Res. 288, 267-278.

934 Garg, S.K., 1989. Effect of Pinealectomy, Eye Enucleation, and Melatonin Treatment on Ovarian Activity and Vitellogenin Levels in The Catfish Exposed to Short Photoperiod or Long Photoperiod. J. Pineal Res. 7, 91-104.

Gern, W.A., Greenhouse, S.S., Nervina, J.M., Gasser P.J., 1992. The rainbow trout pineal organ: an endocrine photometer. In: Ali, M.A., ed., Rhythms in Fish. Plenum, New York; pp. 199-218.

Gern, W.A., Owens, D.W., Ralph, C.H. L., 1978. The Synthesis of Melatonin by the Trout Retina. J. Exp. Zool. 206, 263-270.

González-Martínez, D., Zmora, N., Mañanos, E., Saligaut, D., Zanuy, S., Zohar, Y., Elizur, A., Kah, O., Muñoz-Cueto, J.A, 2002. Immunohistochemical localization of three different prepro-GnRHs (Gonadotrophin-releasing hormones) in the brain and pituitary of the European sea bass (Dicentrarchus labrax) using antibodies against recombinant GAPs. J. Comp. Neurol .446, 95-113.

González-Martínez, D., Madigou, T., Mananos, E., Cerdá-Reverter, J.M., Zanuy, S., Kah, O.,

Grace, M.S., Cahill, G.M., Besharse, J.C., 1991. Melatonin deacetylation: retinal vertebrate class distribution and Xenopus laevis tissue distribution. Brain Res. 559, 56-63.

953 Gwinner, E., 1986. Circannual Rhythms, Springer-Verlag, Heidelberg.

954 Hansen, T., Karlsen, O., Taranger, G.L., Hemre, G.-I., Holm, J.C., Kjesbu, O.S., 2001. Growth, gonadal development and spawning time of Atlantic cod (Gadus morhua) reared under different photoperiods. Aquaculture 203, 51-67. 
Cloning and expression of a MT1 melatonin receptor in the European sea bass (Dicentrarchus labrax), pp. 67-72 in Avanços em Endocrinologia Comparativa Vol. III, edited by A.V.M. Canario and D.M. Power. CCMAR Universidade do Algarve, Faro.

961

962

963

964

965

966

967

Holmqvist, B., Östholm, T., Ekström, P., 1992. DiI tracing in combination with immunocytochemistry for analysis of connectivities and chemoarchitectonics of specific neural systems in a teleost, the Atlantic salmon. J. Neurosci. Meth. 42, 45-63.

Iigo, M., Abe, T., Kambayashi, S., Oikawa, K., Masuda, T., Mizusawa, K., Kitamura, S., Azuma, T., Takagi, Y., Aida, K. and Yanagisawa, T., 2007. Lack of Circadian Regulation of in vitro Melatonin Release From the Pineal Organ of Salmonid Teleosts. Gen. Comp. Endocrinol. 154, 91-97.

Iigo, M., Furukawa, K.H.A., Ohtani-Kaneko, R., Hara, M., Suzuki, T., Tabata, M. and Aida, K., 1997a. Ocular Melatonin Rhythms in the Goldfish, Carassius Auratus. J. Biol. Rhythms 12, 182-192.

Iigo, M., Sanchez-Vasquez, F. J., Madrid, J. A., Zamora, S. and Tabata, M., 1997b. Unusual Responses to Light and Darkness of Ocular Melatonin in European Sea Bass. Neuroreport 8, 1631-1635.

Iuvone, P.M., Tosini, G., Pozdeyev, N., Haque, R., Klein, D.C. and Chaurasia, S.S., 2005. Circadian clocks, clock networks, Arylalkylamine N-Acetyltransferase, and melatonin in the retina. Prog. Retin. Eye Res. 24, 433-456.

Jiménez, A.J., Fernández-Llébrez, P., Pérez-Fígares, J.M., 1995. Central projections from the goldfish pineal organ traced by HRP-immunocytochemistry. Histol. Histopathol. 10, 847852.

Kah, O., Anglade, I., Leprétre, E., Dubourg, P., de Monbrison, D., 1993. The reproductive brain in fish. Fish Physiol. Biochem. 11, 85-98.

Kavalier, M., 1989. Day-night rhythms of shoaling behavior in goldfish: opioid and pineal 
involvement. Physiol Behav. 46, 167-172.

984 Kazimi, N., Cahill, G.M., 1999. Development of a circadian melatonin rhythm in embryonic zebrafish. Brain Res. Dev. Brain Res. 117, 47-52.

986

Khan, I.A., Thomas, P., 1996. Melatonin influences gonadotropin II secretion in the Atlantic croaker (Micropogonias undulatus). Gen. Comp. Endocrinol. 104, 231- 242

Klein, D. C., Coon, S.L., Roseboom, P.H., Weller, J.L., Bernard, M., Gastel, J.A., Zatz, M., Iuvone, P.M., Rodriguez, I.R., Begay, V., Falcón, J., Cahill, G.M., Cassone, V.M. and Baler, R., 1997. The Melatonin Rhythm-Generating Enzyme: Molecular Regulation of Serotonin N-Acetyltransferase in the Pineal Gland. Recent Program in Hormone Research 52, 307-356.

Kulczykowska, E., Kalamarz, H., Warne, J.M., Balment, R.J., 2006. Day-night specific binding of 2-[125I]iodomelatonin and melatonin content in gill, small intestine and kidney of three fish species. J. Comp. Physiol. [B] 176, 277-285.

Lopez-Olmeda, J.F., Madrid, J.A., Sanchez-Vasquez, F.J., 2006. Light and temperature cycles as zeitgebers of zebrafish (Danio rerio) circadian activity rhythms. Chronobiol. Int. 23, 537-550.

Lundmark, P.O., Pandi-Perumal, S.R., Srinivasan, V., Cardinali, D.P., 2006. Role of melatonin in the eye and ocular dysfunctions. Vis. Neurosci. 23, 853-862.

Mandado, M., Molist, P., Anadón, R., Yáñez, J., 2001. A DiI-tracing study of the neural connections of the pineal organ in two elasmobranchs (Scyliorhinus canicula and Raja montagui) suggests a pineal projection to the midbrain GnRH-immunoreactive nucleus. Cell Tissue Res. 303, 391-401.

Martinez-Chavez, C.C., Al-Khamees, S., Campos-Mendoza, A. Penman, D. J., Migaud, H., 2008. Clock controlled endogenous melatonin rhythms in Nile tilapia (Oreochromis niloticus niloticus) and African catfish (Clarias gariepinus). Chronobiol. Int. 25, 1, 31 - 
1009 Masuda T., Iigo, M., Katsumi A., 2005. Existence of an extra-retinal and extra-pineal 1010 photoreceptive organ that regulates photoperiodism in gonadal development of an 1011 Osmerid teleost, ayu (Plecoglossus altivelis). Comp. Biochem. Physiol. Part A 140, 414422.

1013 Max, M, Menaker, M., 1992. Regulation of melatonin production by light, darkness, and 1014 temperature in the trout pineal. J. Comp. Physiol. A 170, 479-489.

1015 Mayer, I., Bornestaf, C., Borg, B., 1997. Melatonin in non-mammalian vertebrates: physiological role in reproduction? Comp. Biochem. Physiol. 118A, 515-531.

Mayer, I., 2000. Effect of long-term pinealectomy on growth and precocious maturation in 1018 Atlantic salmon, Salmo salar parr. Aquat. Living Resour. 13, 139-144.

1019 Migaud, H., Davie, A., Martinez Chavez, C.C., Al-Khamees, S., 2007. Evidence for Differential Photic Regulation of Pineal Melatonin Synthesis in Teleosts. J. Pineal Res. $43,327-335$.

1022

Migaud, H., Taylor, J.F., Taranger, G.L., Davie, A., Cerda-Reverter, J.M., Carrillo, M., 1023 Hansen, T., Bromage, N.R., 2006. A Comparative Ex Vivo and in Vivo Study of Day and Night Perception in Teleosts Species Using the Melatonin Rhythm. J. Pineal Res. 41, 42-

Morgan, A.L, Thompson, K.D., Auchinachie, N.A., Migaud, H., 2008. The effect of seasonality on normal haematological and innate immune parameters of rainbow trout! oncorhynchus mykiss L. Fish Shellfish Immunol., doi:10.1016/j.fsi.2008.05.011

Nakanishi, T., 1986. Seasonal changes in the humoral immune response and the lymphoid tissues of the marine teleost, Sebastiscus marmoratus. Vet. Immunol. Immunopathol. 12, 213-21.

1032 Nguyen, N., Stellwag, E.J., Zhu, Y., 2008. Prolactin-dependent modulation of organogenesis 
in the vertebrate: Recent discoveries in zebrafish. Comp. Biochem. Physiol. Part C. doi:10.1016/j.cbpc.2008.05.010

O’Brien, P.J., Klein, D.C., 1986. Pineal and Retinal Relationships. Orlando: Academic Press.

Okano, K., Okano, T., Yoshikawa, T., Masuda, A., Fukada, Y., Oishi, T., 2000. Diversity of opsin immunoreactivities in the extraretinal tissues of four anuran amphibians. J. Exp. Zool. Part A 286, $136-142$.

Oki, H, Yamada N, Ozeki Y, Yamane, H., Kato, N., 1998. Minimum light intensity required to suppress nocturnal melatonin concentration in human saliva. Neurosc. Lett. 252, 9194.

Oliveira, C., Ortega, A., Lopez-Olmeda, J., Vera, L.M., Sanchez-Vasquez, F.J., 2007. Influence of constant light and darkness, light intensity, and light spectrum on plasma melatonin rhythms in Senegal sole. Chronobiol. Int. 24, 615-627.

Omura, Y., Oguri, M., 1969. Hystological studies on the pineal organ of 15 species of teleosts. Bull Jup Soc Scient Fish. 35: 991-1000.

Park, Y.J., Park ,J.G., Kim, S.J., Lee, Y.D., Rahman, M.S., Takemura, A., 2006. Melatonin receptor of a reef fish with lunar-related rhythmicity: cloning and daily variations. $J$. Pineal Res. 41, 166-174.

Pasqualetti, M., Bertolucci, C., Ori, M., Innocenti, A., Magnone, M.C., De Grip, W.J., Nardi, I., Foà, A., 2003. Identification of circadian brain photoreceptors mediating photic entrainment of behavioural rhythms in lizards. Eur. J. Neurosc. 18, $364-372$.

Paul, M.J., Zucker, I., Schwartz, W.J. 2008. Tracking the seasons: the internal calendar of vertebrates. Philos. Trans. R. Soc. London, Ser. B 363, 341-361

Pautler, E.L., Hall, F.L., 1987. Movement of melatonin across the retinal pigment epithelium, Exp. Eye Res. 45, 351-355.

Philp, A.R., Bellingham, J., García-Fernandez, J.M., Foster, R.G., 2000a. A novel rod-like 
opsin isolated from the extraretinal photoreceptors of teleost fish. FEBS Lett. 468, 181188.

1060 Philp, A.R., García-Fernandez, J.M., Soni, B.G., Lucas, R.J., Bellingham, J., Foster, R.G.,

1061 2000b. Vertebrate ancient (VA) opsin and extraretinal photoreception in the Atlantic 1062 salmon (Salmo salar). J. Exp. Biol. 203, 1925-1936.

1063 Ping, Y., Huang, H., Zhang, X.-J., Yang, X.-L., 2008. Melatonin potentiates rod signals to 1064 ON type bipolar cells in fish retina. J. Physiol., in Press.

1065 Pinillos, M.L., De Pedro, N., Alonso-Gómez, A.L., Alonso-Bedate, M., Delgado, M.J., 2001.

1066 Food intake inhibition by melatonin in goldfish (Carassius auratus). Physiol. Behav. 72, $1067 \quad 629-634$.

1068 Pombal, M.A., Yáñez, J., Marín, O., González, A., Anadón, R., 1999. Cholinergic and 1069 GABAergic neuronal elements in the pineal organ of lampreys, and tract-tracing 1070 observations of differential connections of pinealofugal neurons. Cell Tissue Res. 295.

1072 Poncin, P., 1991. Environmental and endocrine control of Barbel (Barbus barbus) 1073 reproduction, pp. 148-150 in Proceedings IV International Symposium on Reproductive 1074 Physiology of Fish, edited by A.P., Scott, J. Sumpter, D. Kime, M. Rolfe. Sheffield, Fish $1075 \quad$ Symp. 91.

1076 Popek, W., Uszczek-Trojnar, E., Drng-Kozak, E., Fortuna-Wroska, D., Epler, P., 2005. Effect 1077 of the pinal gland and melatonin on dopamine release from perifused hypothalamus of 1078 mature female carp during spawning and winter regression. A. Ichthyol. Piscatoria 35 (2), $1079 \quad 65-71$.

1080 Porter, M.J.R., Duncan, N.J., Mitchell, D., Bromage, N.R., 1998. The use of cage lighting to 1081 reduce plasma melatonin in Atlantic salmon (Salmo salar) and its effects on the 1082 inhibition of grilsing. Aquaculture 176, 237-244. 
1083 Prat, F., Zanuy, S., Bromage, N., Carrillo, M., 1999. Effects of constant short and long 1084 photoperiod regimes on the spawning performance and sex steroid levels of female and male sea bass. J. Fish Biol. 54, 125-137.

1086 Randall, C.F., Bromage, N.R., Duston, J., Symes, J., 1998. Photoperiod induced phase-shifts 1087 of the endogenous clock controlling reproduction in the rainbow trout: A circannual 1088 phase-response curve. J. Reprod. Fert. 112, 399-405.

1089 Randall, C.F., Bromage, N.R., Porter, M.J.R., Gardener, J., Auchinachie, N.A., 1999. 1090 Circannual rhythms of reproduction in rainbow trout, pp. 325-327 in Proceedings of $\mathrm{VI}^{\text {th }}$ 1091 International Symposium on Reproductive Physiology of fish, Bergen 4-9 July, edited by 1092 G. L.Taranger, B. Norberg, S. Stefansson, T.Hansen, O. Kjesbu, E. Andersson. Bergen, 2000.

1094 Reppert, S.M., Weaver, D.R., 2002. Coordination of circadian timing in mammals. Nature 1095 $418,935-941$.

1096 Rodríguez, L., Zanuy, S., Carrillo, M., 2001. Influence of daylength on the age at first 1097 maturity and somatic growth in male sea bass (Dicentrarchus labrax, L.) Aquaculture $1098 \quad 196: 159-175$.

1099 Rubio, V.C. Sánchez-Vázquez, J., Madrid, J.A., 2004. Oral administration of melatonin 1100 reduces food intake and modifies macronutrient selection in European sea bass 1101 (Dicentrarchus labrax, L.). J. Pineal Res. 37, 42-47

1102 Sakharkar A, Singru P, Subhedar N, 2005. Reproduction phase-related variations in the 1103 GnRH immunoreactive fibers in the pineal of the Indian major carp Cirrhinus mrigala 1104 (Ham.). Fish Physiol. Biochem. 31, 163-166.

1105 Sauzet, S., Besseau, L., Herrera Perez P., Covès D., Chatain B., Peyric E., Boeuf G., Muñoz1106 Cueto J.A., Falcón, J., 2008. Cloning and retinal expression of melatonin receptors in the 1107 European sea bass, Dicentrarchus labrax. 157, 186-195. 
1108 Sébert, M.E., Legros, C., Weltzien, F.A., Malpaux, B., Chemineau. P., Dufour, S., 2008. Melatonin activates brain dopaminergic systems in the eel with an inhibitory impact on reproductive function. J. Neuroendocrinol. 20, 917-929.

1111 Servili, A., López-Olmeda, J.F., Herrera, P., Sánchez-Vázquez, F.J., Muñoz-Cueto, J.A., 2007. Gonadotrophin-releasing hormone modulates the secretion of melatonin in sea bass, Dicentrarchus labrax, pp. 89-93 in Avanços em Endocrinologia Comparativa Vol. III, edited by A.V.M. Canario and D.M. Power. CCMAR Universidade do Algarve, Faro.

Servili. A., Herrera, P., Rendón, M.C., Bayarri, M.J., Sánchez-Vázquez, F.J., Muñoz-Cueto, J.A., 2005. Estudio morfofuncional de la glándula pineal de la lubina: análisis de sus conexiones eferentes y aferentes, pp. 175-180 in Avances en Endocrinología Comparada,

Simonneaux, V, Ribelayga, C. 2003. Generation of the melatonin endocrine message in mammals: A review of the complex regulation of melatonin synthesis by norepinephrine, peptides, and other pineal transmitters. Pharmacol. Rev. 55, 325-395.

Siu, A.W., Maldonado, M., Sanchez-Hidalgo, M., Tan, D.X., Reiter, R.J., 2006. Protective Effects of Melatonin in Experimental Free Radical-Related Ocular Diseases. J. Pineal Res. 40, 101-109.

Slater, C.H., Schreck, C.B., 1998. Season and physiological parameters modulate salmonid leucocyte androgen receptor affinity and abundance. Fish Shellfish Immunol. 8,379-91.

1128 Spieler, R. E., Circadian timing of meal feeding and growth in fishes. Reviews in Fisheries $1129 \quad$ Science, 9:115-131.

1130 Subhedar, N., Cerdá, J., Wallace, R.A.., 1996. Neuropeptide Y in the forebrain and retina of 1131 the killifish, Fundulus heteroclitus. Cell Tissue Res. 283, 313-323.

1132 Sumpter, J.P., 1992. Control of growth of rainbow-trout (Oncorhynchus-mykiss). 
Aquaculture, 100: 299-320.

1134 Sundararaj, B., Vasal, S., Halver, F., 1982. Circannual rhythmic ovarian recrudescence in the catfish. Adv. Biosci. 41, 319-337.

Taylor, J.F., Migaud, H., Porter, M.J.R., Bromage, N.R. 2005. Photoperiod influences growth rate and plasma insulin-like growth factor-I levels in juvenile rainbow trout, Oncorhynchus mykiss. Gen. Comp. Endocrinol. 142, 169-185.

Tosini, G., Fukuhara, C., 2003. Photic and circadian regulation of retinal melatonin in mammals. J. Neuroendocrinol. 15, 364-369.

1141 Tricoire, H, Locatelli, A, Chemineau, P, Malpaux, B., 2002. Melatonin enters cerebrospinal

1142 fluid through the pineal recess. Endocrinology 143, 84-90.

1143 Underwood H., Barrett R.K., Siopes, T., 1990. Melatonin does not link the eyes to the rest of 1144 the circadian system in quail: a neural pathway is involved. J. Biol. Rhythms 5, 349-361.

1145 Underwood, H., Hyde, L.L., 1989. The effect of daylength on the pineal melatonin rhythm of 1146 the lizard Anolis carolinensis. Comp. Biochem. Physiol. 94A, 53-56

1147 Vallone, D., Lahiri, K., Dickmeis, T., Foulkes, N.S., 2005. Zebrafish Cell Clocks Feel the $1148 \quad$ Heat and See the Light! Zebrafish 2, 171-187.

1149 Vera L.M., Lopez-Olmeda J.F., Bayarri M.J., Madrid J.A., Danchez-Vazquez F.J., 2005. 1150 Influence of light intensity on plasma melatonin and locomotor activity rhythms in tench. $1151 \quad$ Chronbiol. Int. 22, 67-78.

1152 Vernadakis, A.J., Bemis, W.E., Bittman, E.L., 1998. Localization and partial characterization 1153 of melatonin receptors in amphioxus, hagfish, lamprey, and skate. Gen. Comp. $1154 \quad$ Endocrinol. 110, 67-78.

1155 Vigh, B., Manzano, M.J., Zádori, A., Frank, C.L., Lukáts, A., Röhlich, P., Szél, A., Dávid, C., 1156 2002. Nonvisual photoreceptors of the deep brain, pineal organs and retina. Histol. $1157 \quad$ Histopathol. 17, 555-590. 
von Frisch, K. 1911. Beiträge zur Physiologie der Pigmentzellen in der Fischhaut. Pflügers Arch 138:319-387.

Vuilleumier R., Boeuf G., Fuentes M., Gehring W.J., Falcón J., 2007. Cloning and early expression pattern of two melatonin biosynthesis enzymes in the turbot (Scophthalmus maximus). European J. Neurosc. 25, 3047-3057.

Whitmore, D., Foulkes, N.S., Strahle, U., Sassone-Corsi, P., 1999. Zebrafish Clock rhythmic expression reveals independent peripheral circadian oscillators. Nature neuroscience, $\mathbf{1}$, 701-707.

Wirsig-Wiechmann, C.R., Wiechmann, A.F., 2002. Vole retina is a target for gonadotropinreleasing hormone. Brain Res. 950, 210-217.

Wojtowicz, A., Plytycz, B., 1997. Seasonal changes of the gutassociated lymphoid tissue in the common toad, Bufo bufo. J. Nutr. Immunol. 5, 57-64.

Yáñez, J., Anadón, R.,, Holmqvist, B. I., and Ekström, P., 1993. Neural projections of the pineal organ in the larval lamprey (Petromyzon marinus L.) revealed by indocarbocyanine dye tracing. Neurosci. Lett. 164: 213-216.

Yáñez, J., Anadón, R.,1998. Neural connections of the pineal organ in the primitive bony fish Acipenser baeri: a carbocyanine dye tract-tracing study. J. Comp. Neurol. 398,151-161.

Yoshikawa, T., Yashiro, Y., Oishi, T., Kokame, K., Fukada, Y., 1994. Immunoreactivities to rhodopsin and rod/cone transducin antisera in the retina, pineal complex and deep brain of the bullfrog, Rana catesbeiana. Zool. Sci. 11, 675-680.

Zachmann, A., Falcón, J., Knijff, S.C.M., 1992. Effects of photoperiod and temperature on rhythmic melatonin secretion from the pineal organ of the white sucker (Catostomus commersoni) in vitro. Gen. Comp. Endocrinol. 86, 26-33.

Zapata, A.G., Varas, V., 1992. Torroba M. Seasonal variations in the immune system of lower vertebrates. Immunol. Today 13,142-7. 
1183 Zhdanova, I.V., Wang, S.Y., Leclair, O.U., Danilova, N.P. 2001. Melatonin promotes sleep1184 like state in zebrafish. Brain Research. 903:263-268.

1185 Zilberman-Peled, B., Ron, B., Gross, A., Finberg, J.P.M., Gothilf, Y.. 2006. A possible new 1186 role for fish retinal serotonin-N-acetyltransferase-1 (AANAT1): Dopamine metabolism. $1187 \quad$ Brain Res. 1073, 220-228.

1188 Zilberman-Peled, B., Appelbaum L., Vallone D., Foulkes N.S., Anava S., Anzulovich, A., 1189 Coon, S.L., Klein, D.C., Falcón, J., Ron, B., Gothilf, Y., 2007. Transcriptional Regulation 1190 of Arylalkylamine- $N$-Acetyltransferase-2 Gene in the Pineal Gland of the Gilthead 1191 Seabream. J. Neuroendocrinol. 19, 46-53.

1192 Ziv, L., Levkovitz, S., Toyama, R., Falcón, J., Gothilf Y., 2005. Functional development of 1193 the zebrafish pineal gland: light-induced expression of period2 is required for onset of the 1194 circadian clock, J. Neuroendocrinol. 17, 314-320.

1195 
1198 Figure 1. Photoperiodic and circadian control of neuroendocrine functions. (a) Fish versus

1199 mammals. In mammals (i) a linear flow leads to the rhythmic production of melatonin. 1200 Nonvisual information from the retina reaches the SCN of the hypothalamus through the 1201 retinohypothalamic tract (blue arrow). The periodic signals enable synchronizing of the 1202 circadian activity of the SCN clocks, which, in turn, impact on the pineal gland through a multisynaptic pathway (blue arrows), thus controlling cyclical melatonin secretion. Melatonin feeds back to the SCN and acts on the pars tuberalis of the pituitary and other brain areas to modulate seasonal neuroendocrine functions. The situation is more complex in fish (ii): the

1206 photoneuroendocrine system seems to be organized as a network of independent and 1207 interconnected light-sensitive oscillatory units in the retina, the pineal and, perhaps, in the brain. The dashed blue arrow indicates a hypothetical connection. '?' in the brain indicates the hypothetical presence of brain circadian oscillators. (b) Photoneuroendocrine regulation in fish. Light (yellow arrows) impacts on photoreceptor cells of the pineal organ and retina, 1211 enabling synchronization of their internal molecular clocks. Light might also impact on other 1212 possible photosensitive and circadian structures in the ventral diencephalon (POA and 1213 hypothalamic area; yellow arrow with '??') and peripheral organs. In response to the 1214 photoperiodic information, the retina and the pineal organ elaborate two types of rhythmic 1215 information. The neural information (blue arrows) from the retina and pineal organ reach the 1216 ventral diencephalon through the retinohypothalamic and the pineal tracts, respectively. This 1217 information provides an indication of day length, as well as of subtle variations in ambient 1218 illumination. The hormonal information is relayed by melatonin (red arrows), the production 1219 of which reflects day length and season. In the retina, melatonin is an autocrine and/or 1220 paracrine factor, which is metabolized locally. Pineal melatonin is released into the 
1221 cerebrospinal fluid and blood, and acts on specific targets through melatonin receptors (red

1222 filled circles). In the hypothalamus, melatonin might contribute to synchronizing the activities 1223 of circadian oscillatory units [SCN and others (depicted by '?')] and modulating the

1224 production of pituitary gland releasing factors. Melatonin receptors have been identified in 1225 areas that impact on pituitary function, including the POA, which also receives nervous input 1226 from both the pineal organ and the retina. Melatonin impacts on the pituitary gland itself to 1227 modulate the production of hormones. Taken from Falcón et al. (2007) with permission.

1229 Figure 2. Melatonin biosynthesis pathway. See text for details. On the top right is indicated a 1230 photoperiodic $24 \mathrm{~L}$ (light) and D (dark) cycle with a schematic indication of the daily 1231 variations in the corresponding compound or enzyme activity. AAAD: aromatic amino-acid 1232 decarboxylase; AANAT: arylalkylamine $\mathrm{N}$-acetyltransferase; HIOMT: hydroxyindole- $O$ 1233 methyltransferase; TP-OH tryptophan hydroxylase;

1234

1235 Figure 3. Irradiance response plots for Atlantic salmon, European sea bass and Atlantic cod 1236 derived from in vitro pineal gland studies (from Migaud et al., 2006, Migaud et al., 1237 unpublished). Arrows indicate theorical in vitro thresholds between day and night.

1239 Figure 4. Diagrammatic representation of the different melatonin profiles recorded in 1240 vertebrates. Examples of species which express such patterns of plasma melatonin for each 1241 profile are listed. Horizontal black bar denotes subjective dark period. 
1242 Figure 5. A. Pinealofugal projections from the sea bass pineal organ reaching the 1243 ventromedial thalamic nucleus (VM). DiI tract tracing analysis. B. Neurons from the 1244 ventromedial thalamic nucleus (VM) projecting to the sea bass pineal organ. DiI tract tracing 1245 analysis. C. Neurons from the ventromedial thalamic nucleus (VM) projecting to the sea bass

1246 pituitary. DiI tract tracing analysis. D. Tyrosine-hydroxylase (catecholaminergic) cells in the 1247 ventromedial thalamic nucleus (VM). Immunohistochemical study.

1249 Figure 6. Screening of the sensitive period for inhibition of maturation of sea bass males at 1250 the first year of life by over-imposition of continuous light of different durations during the 1251 natural autumnal photoperiodic reduction. A sensitivity period is likely placed around August1252 September (Grey area). 2-4 = Carrillo et al., 2008. 5-6 = Felip et al., 2008; $7=$ Begtashi et al. 12532004.

1254

1255 Figure 7. Effects of continuous light (LL) exposure on the seasonal plasma LH daily rhythm 1256 of male sea bass during their first year of life. Suppression of the nocturnal peak of LH 1257 induced an immature state of gonad development and inhibited the appearance of precocious 1258 fish. After Bayarri et al., 2008. Chronobiol. Int. (in press). 
1259 Figure 8. Circannual rhythms of spawning in sea bass maintained under constant short 1260 photoperiod (9 hours light: 15 hours dark; 9HL: 15HD) (B) and constant long photoperiod 1261 (15HL: 9HD) (D) during several consecutive years. The spawning rhythms "free run" with a 1262 period of approximately a year. A constant long photoperiod of one month of duration applied 1263 during May, April or March, in otherwise constant short photoperiod, was used to entrain the 1264 endogenous annual clock. Progressive advances of the spawning time were obtained with 1265 early applications of long days and a return to the free running rhythm was observed after 1266 exposure to constant short days (C). The clock controlled circannual rhythm would be fully in 1267 phase with the ambient light cycle (A) as a result of ongoing re-entrainment by the 1268 seasonally-changing day length and consequently spawning time will occurs at the natural 1269 period of reproduction (dashed area). LP = long photoperiod; SP $=$ short photoperiod. After 1270 Carrillo et al. (1995). 

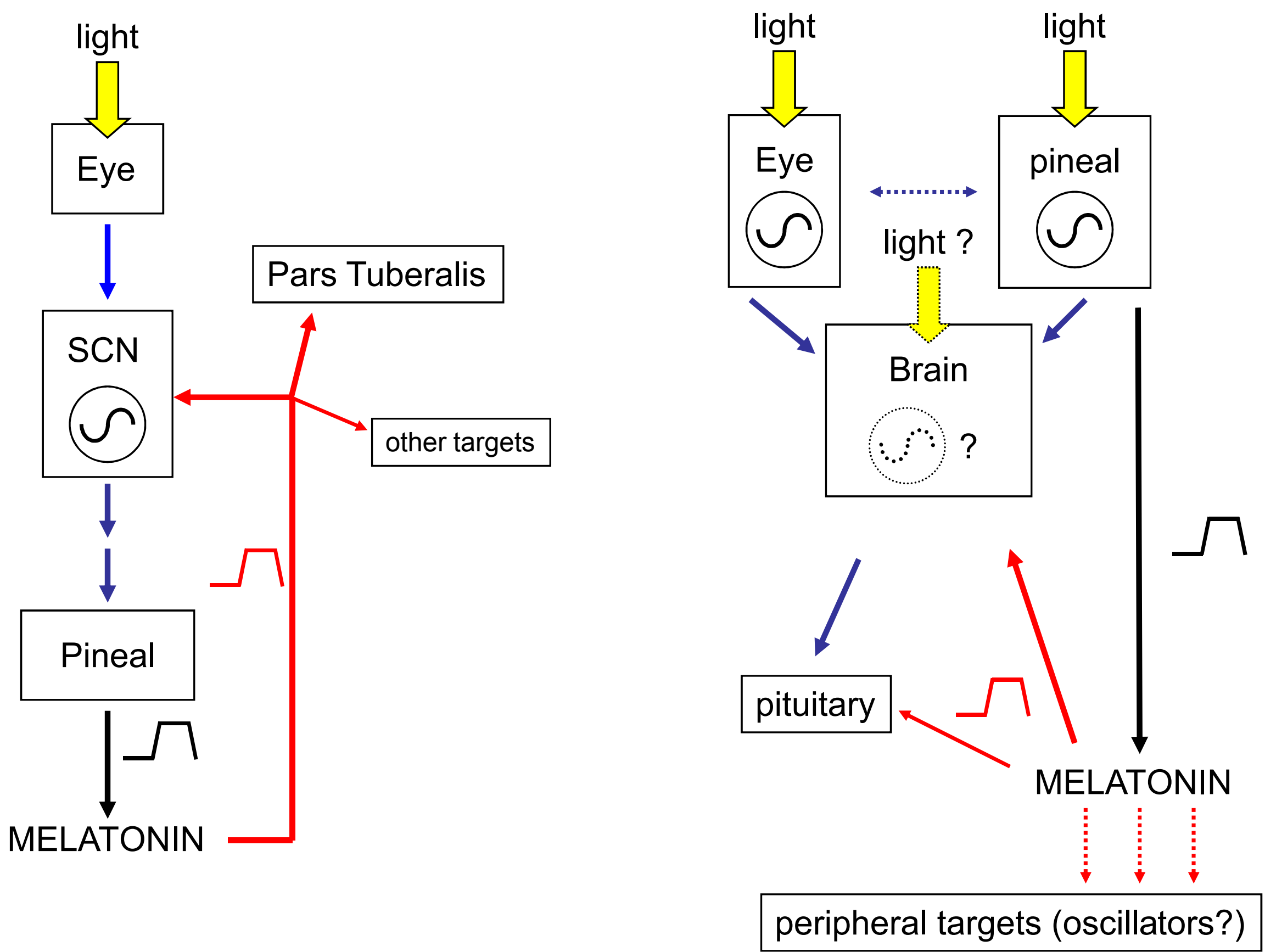


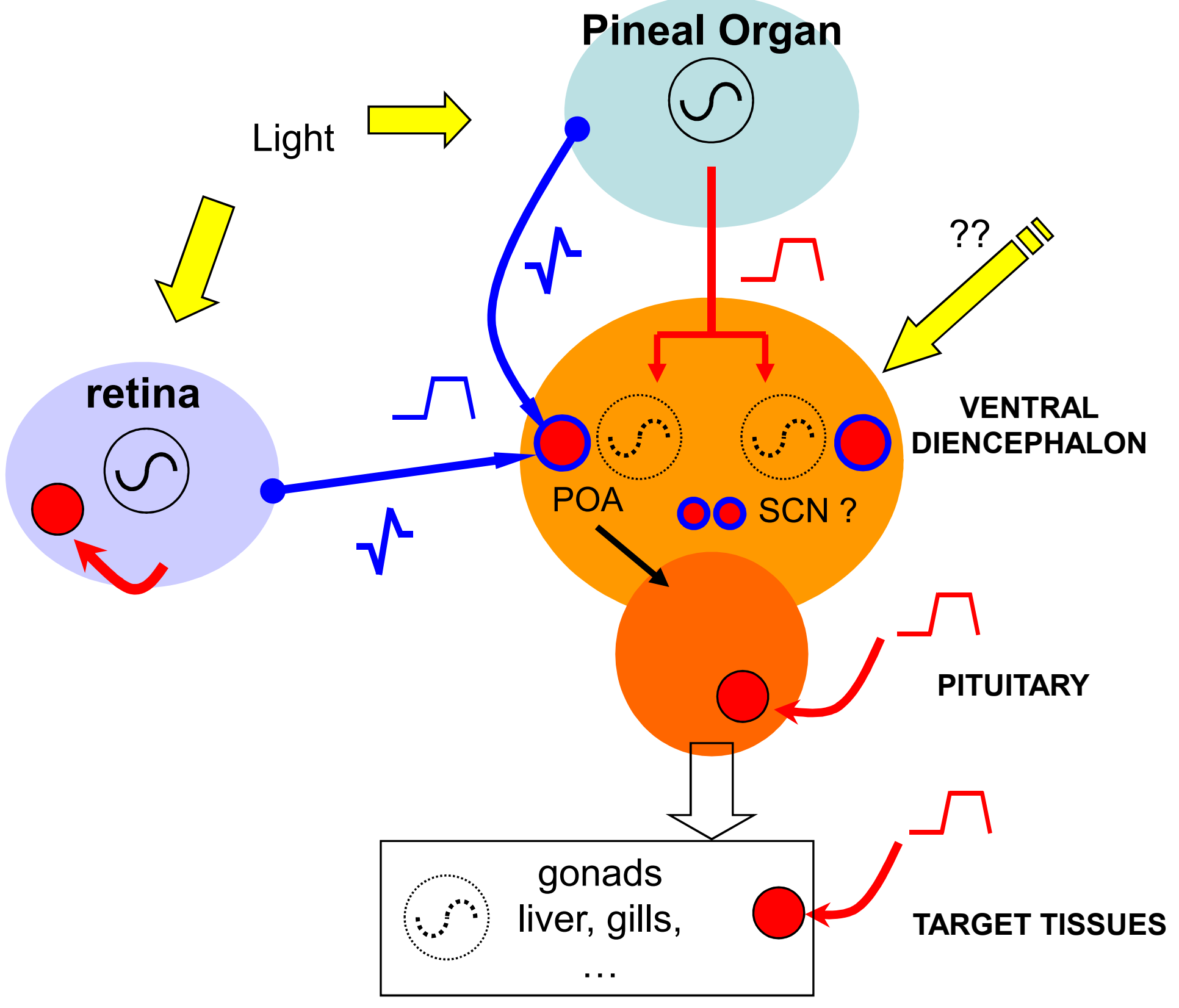


Tryptophan

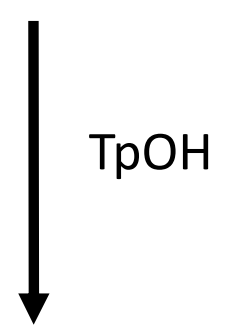

5-hydroxytryptophan

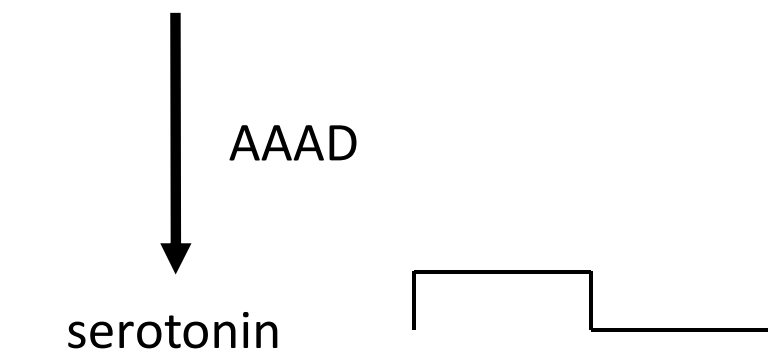

$\downarrow$ AANAT

$\mathrm{N}$-ac-serotonin

Figure 2
L D
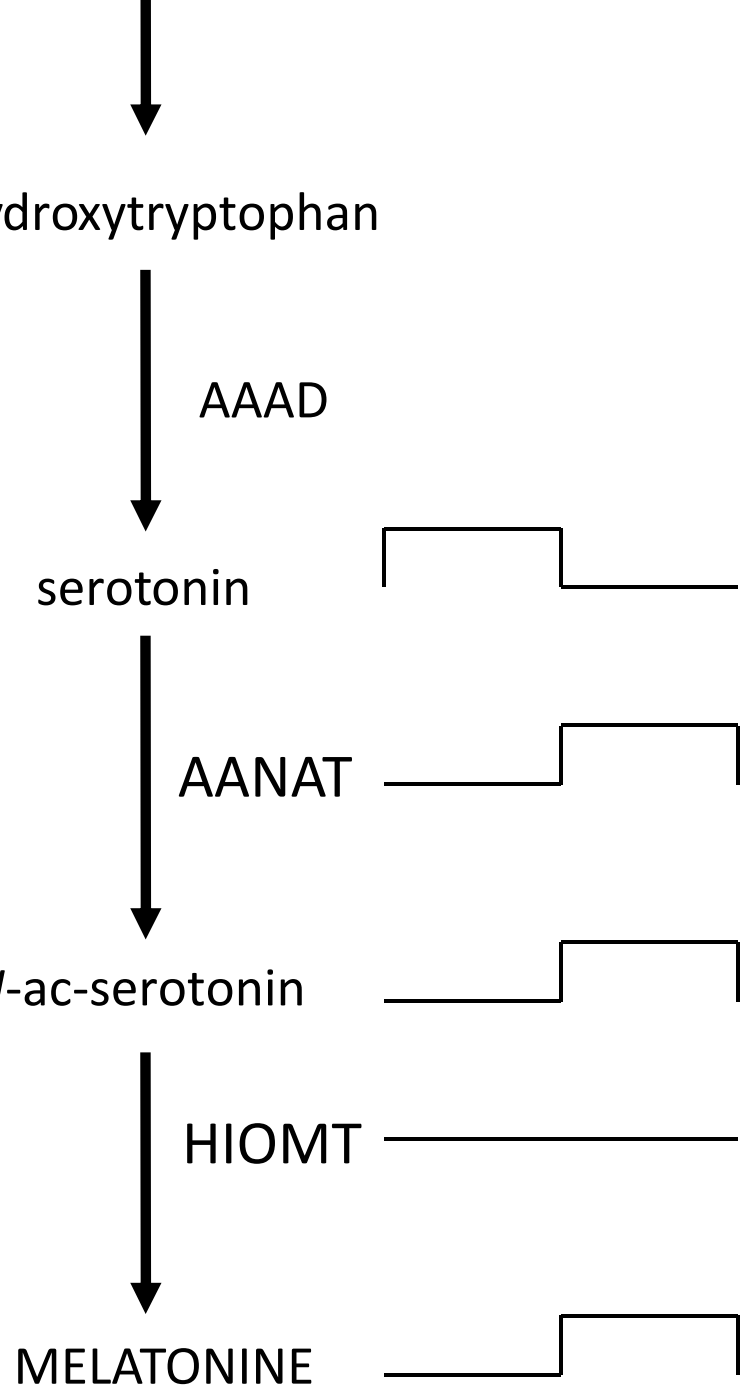


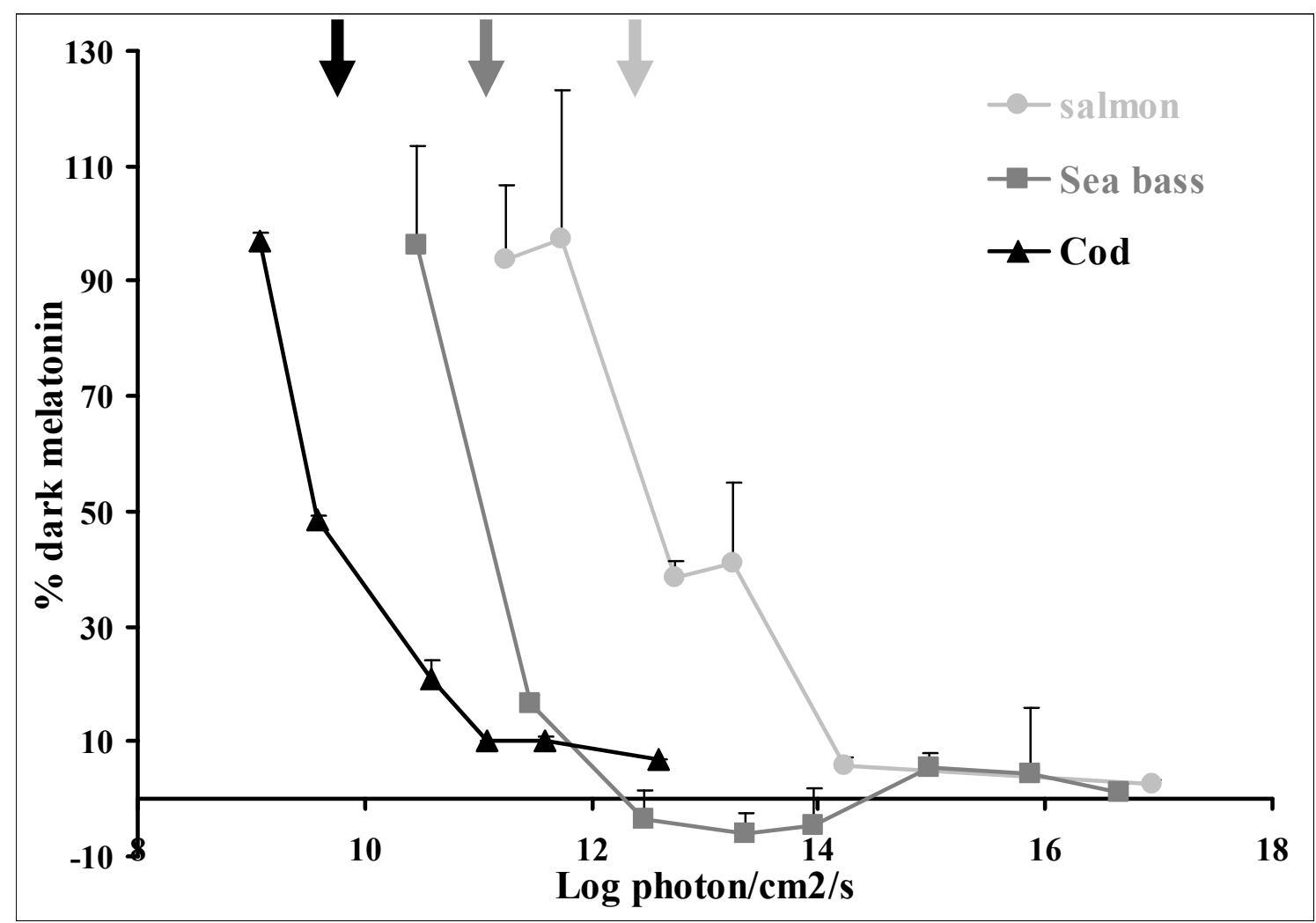

Figure 3 
Figure 4

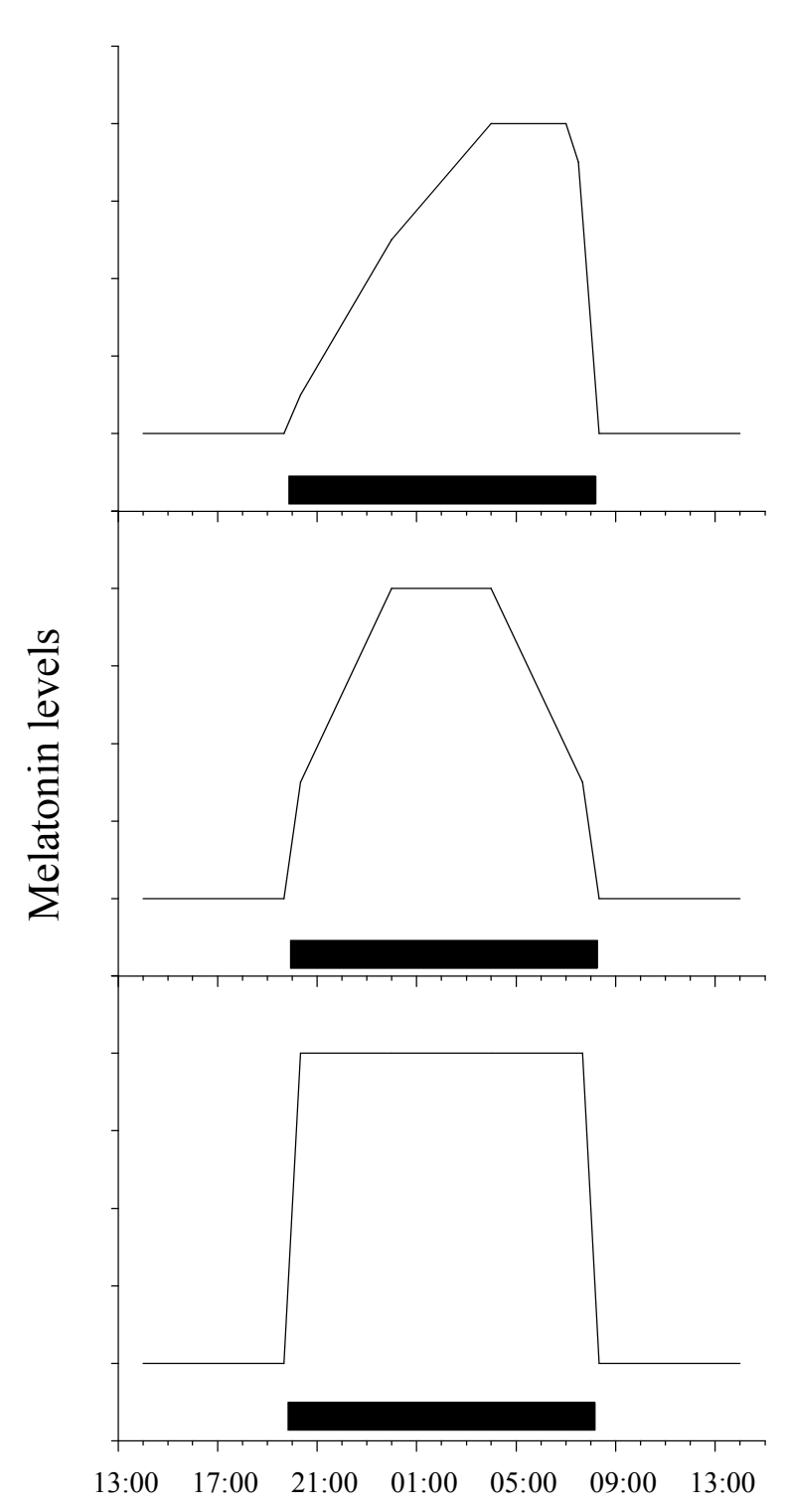

\section{Description of rhythm}

Type A: Discrete peak in late dark phase

Species: Syrian Hamster

Mongoloian Gerbil

House Mouse

Cod

Haddock

Type B: Discrete peak in mid dark phase

Species: Albino Rat

Eastern Chipmunk

Turkish Hamster

Human

Nile Tilapia

Type C: Prolonged peak through the majority of the dark pahse

Species: White - Foot Mouse

Djungarian Hamster

Domestic cat

Sheep

Atlantic salmon

Rainbow trout

Atlantic halibut 


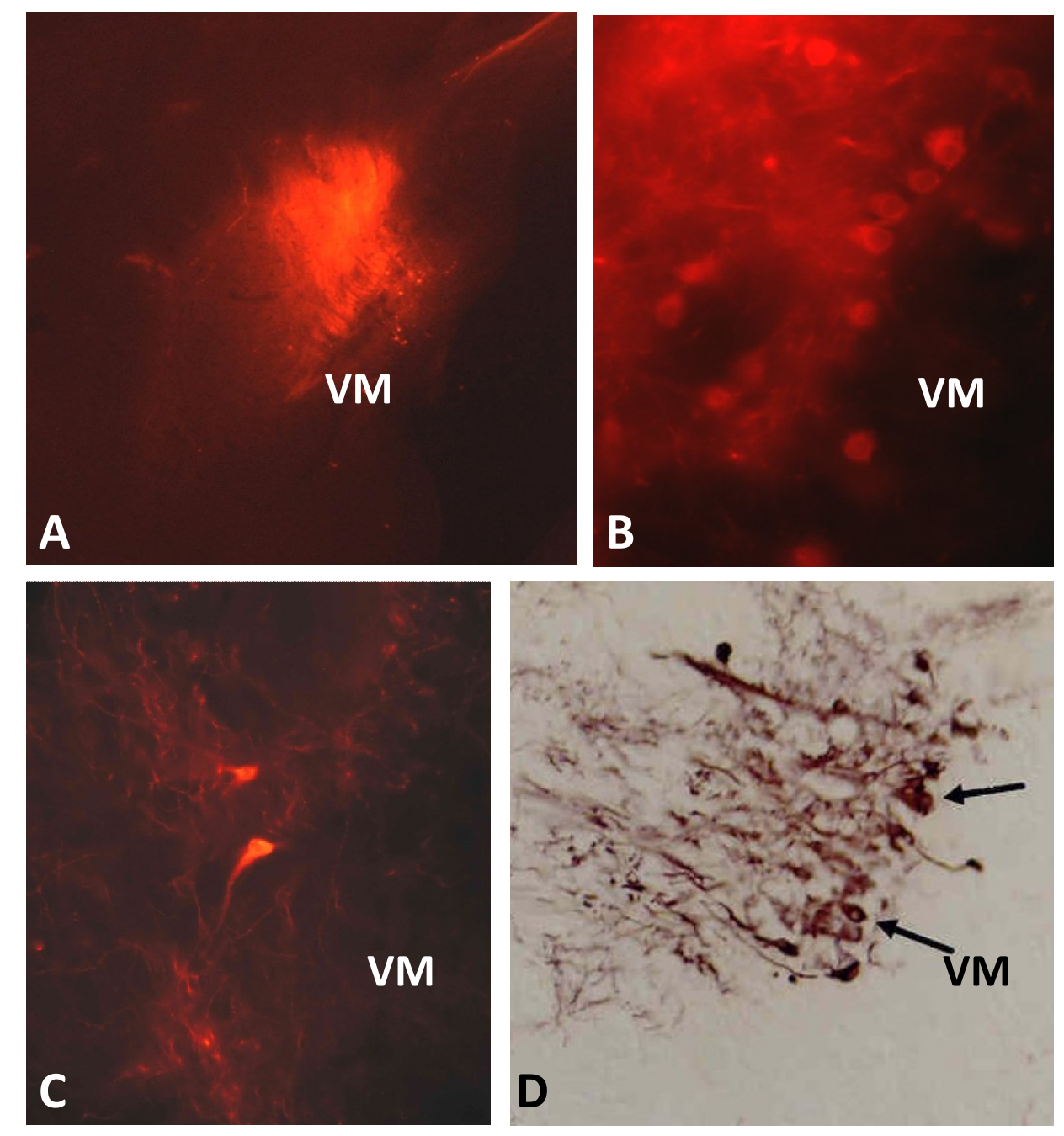




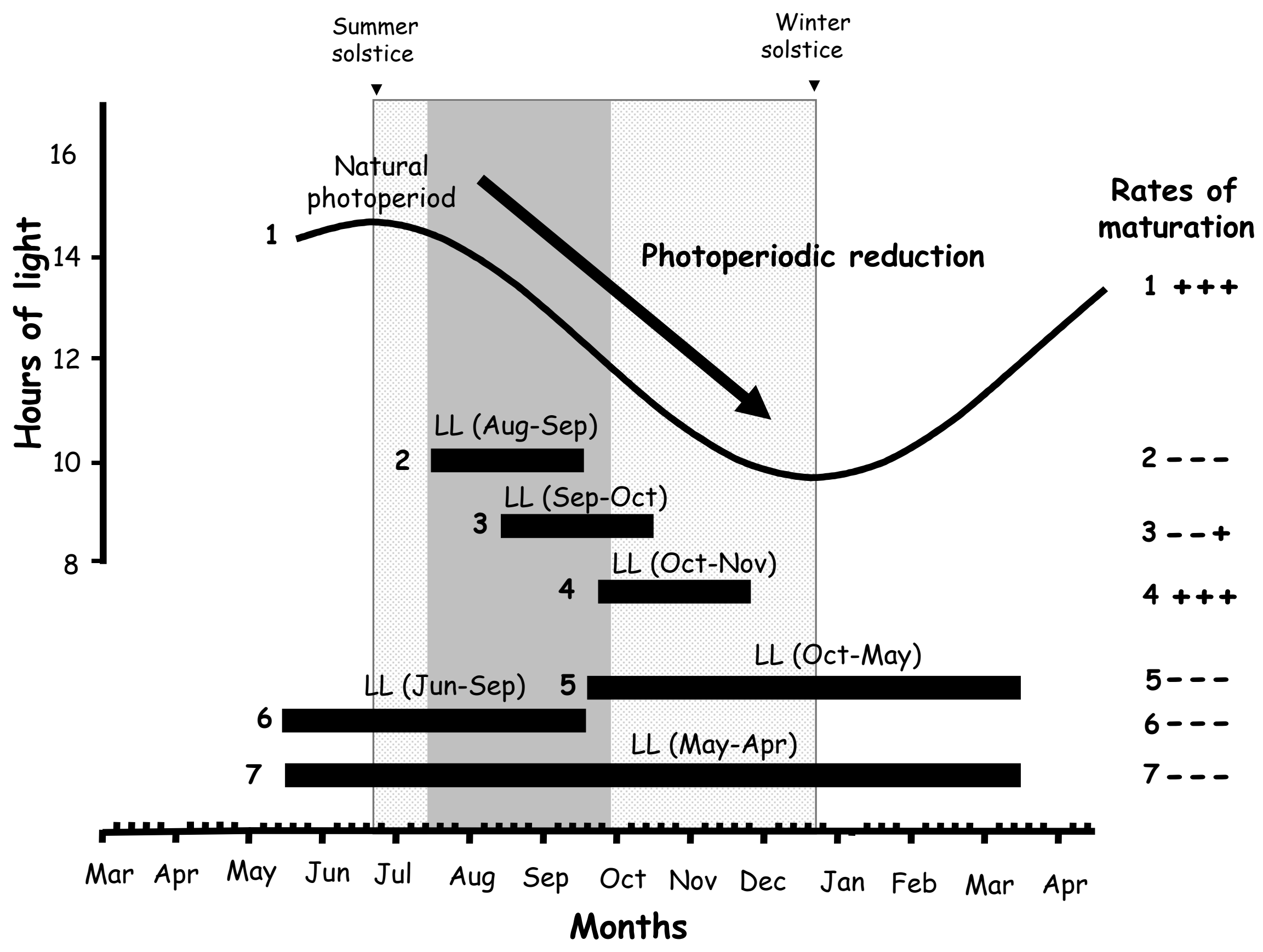



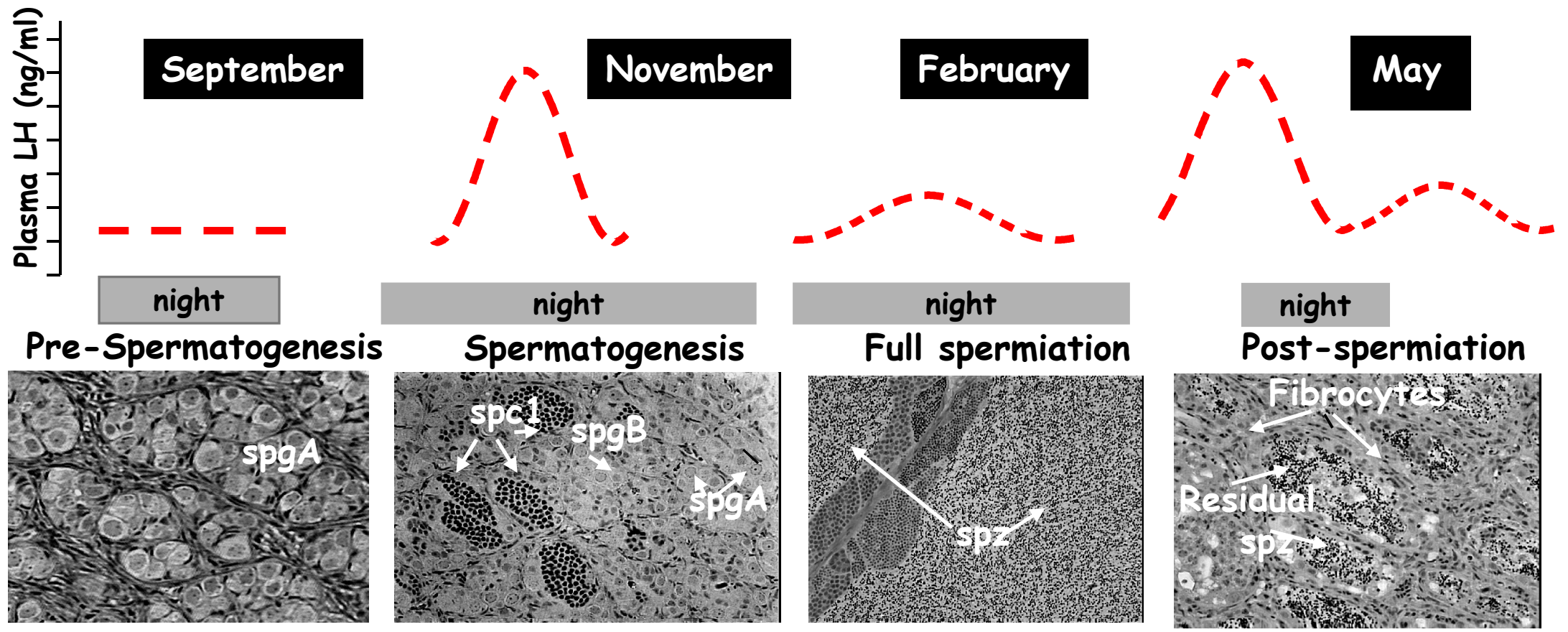

\section{Continuous light exposure (LL)}

Pulsatile secretion of LH could be important to trigger puberty?
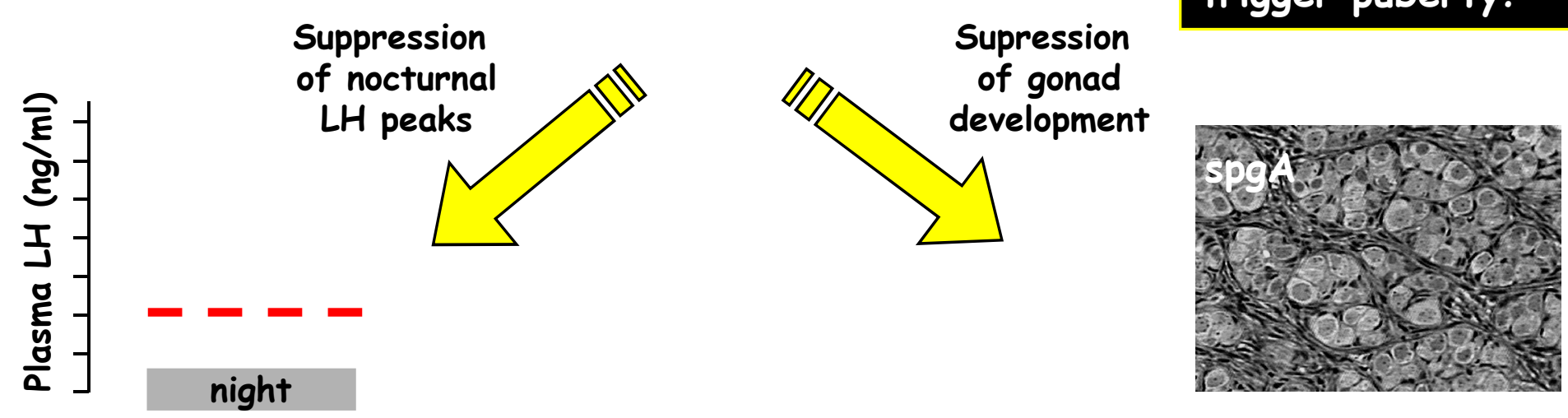

Immature state of development 


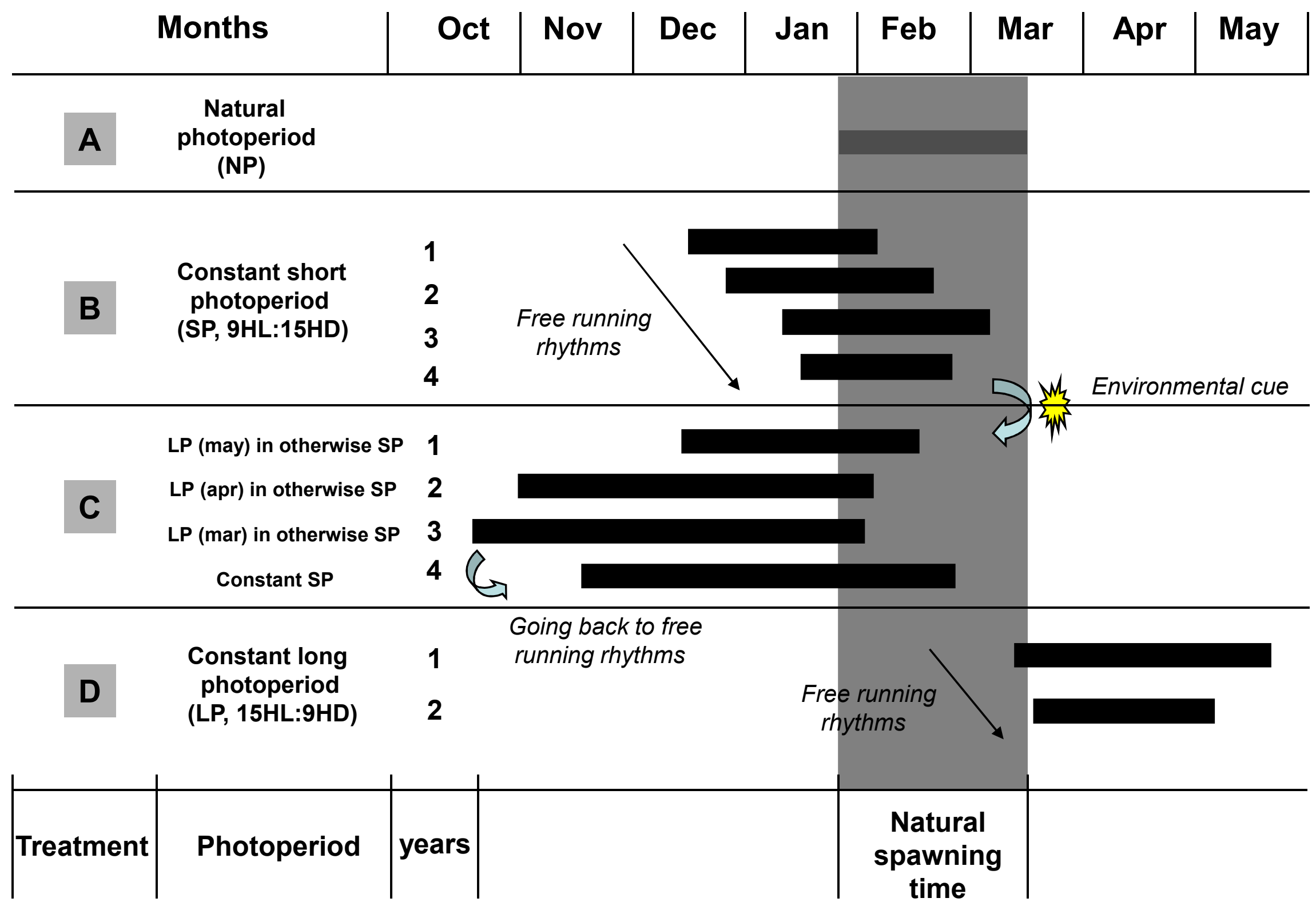

